\title{
Petrographically Quantifying the Damage to Field and Lab-cast Mortars Subject to Freeze-thaw Cycles and Deicer Applications
}

CHUNYU QIAO ( $\sim$ joe@drpcinc.com )

DRP, A Twining Company https://orcid.org/0000-0002-2583-5296

Nima Hosseinzadeh Nanehkaran

University of Miami

Prannoy Suraneni

University of Miami

Sihang Wei

Bintong Engineering

David Rothstein

DRP, A Twining Company

\section{Research Article}

Keywords: Concrete petrography, substrate mortar, calcium oxychloride, freeze-thaw cycles, deicers

Posted Date: March 5th, 2021

DOI: https://doi.org/10.21203/rs.3.rs-271595/v1

License: (c) (1) This work is licensed under a Creative Commons Attribution 4.0 International License.

Read Full License

Version of Record: A version of this preprint was published at Journal of Infrastructure Preservation and Resilience on April 14th, 2021. See the published version at https://doi.org/10.1186/s43065-021-00024-3. 

cycles and deicer applications Chunyu Qiao ${ }^{\mathrm{a} *}$, Nima Hosseinzadeh Nanehkaran ${ }^{\mathrm{b}}$, Prannoy Suraneni ${ }^{\mathrm{b}}$, Sihang Wei ${ }^{\mathrm{c}}$ and David Rothstein ${ }^{\mathrm{a}}$ a. DRP, A Twining Company, Boulder, CO 80301, USA b. Department of Civil, Architectural and Environmental Engineering, University of Miami, Coral Gables, FL 33146, USA c. Bintong Engineering, Shenzhen, Guangdong 518052, China

* Corresponding author: Chunyu Qiao, Email: joe@drpcinc.com

\section{ABSTRACT}

Although calcium oxychloride (Ca-Oxy) is known to damage cementitious materials exposed to calcium chloride $\left(\mathrm{CaCl}_{2}\right)$ deicers, there is little direct observation of Ca-Oxy in the field due to its instability. This paper uses optical microscopy (OM) and scanning electron microscopy coupled with energy dispersive $\mathrm{X}$ ray spectrometry (SEM-EDX) to detect the formed Ca-Oxy and quantify its associated damage in a field mortar subject to freeze-thaw cycles and deicer applications. The characterized damage in the field mortar is compared to that in lab-cast portland cement paste and mortar which are submerged in a $\mathrm{CaCl}_{2} \mathrm{solution}$ of $25 \mathrm{wt} . \%$ under freeze-thaw cycles $\left(-8\right.$ to $\left.25^{\circ} \mathrm{C}\right)$. The field and lab-cast mortars show similar cracking patterns that are parallel to the exposure surface with a variation of $30-45^{\circ}$ in the preferred orientation due to the constraints of sand particles. During each lab-controlled freeze-thaw cycle, the high $\mathrm{CaCl}_{2}$ concentration of 25 wt. \% stabilizes the formed Ca-Oxy, which continually damages the mortar and eventually results in 3-4 times higher crack density compared to that in the field mortar. SEM-EDX analysis confirms the presence of secondary deposits including Friedel's salt, ettringite and Ca-Oxy. Image analysis on thin section photomicrographs shows a reduction of $86.4 \%$ in calcium hydroxide $\left(\mathrm{Ca}(\mathrm{OH})_{2}\right)$ content in the damaged field mortar compared to the undamaged field mortar, suggesting significant leaching of $\mathrm{Ca}(\mathrm{OH})_{2}$ to form $\mathrm{Ca}-\mathrm{Oxy}$ due to the deicer application.

Keywords: Concrete petrography; substrate mortar; calcium oxychloride; freeze-thaw cycles; deicers. 


\section{Introduction}

27 Chloride-based inorganic salts, such as sodium chloride $(\mathrm{NaCl})$, magnesium chloride $\left(\mathrm{MgCl}_{2}\right)$ and calcium chloride $\left(\mathrm{CaCl}_{2}\right)$, are the most commonly used deicing agents on concrete pavements in cold regions for melting snow and ice [1-4]. However, chloride ions from deicing salts can infiltrate or diffuse into the concrete, which accelerates the corrosion of the steel reinforcement and diminish the service life of concrete pavements [5,6]. $\mathrm{MgCl}_{2}$ and $\mathrm{CaCl}_{2}$ can also react with hydration products to form secondary phases such as brucite $\left(\mathrm{Mg}(\mathrm{OH})_{2}\right)$, magnesium-silicate hydrate $(\mathrm{M}-\mathrm{S}-\mathrm{H})$ and calcium oxychloride (Ca-Oxy), that can damage cementitious materials through multiple reactions $[7,8]$ :

$$
\begin{gathered}
\mathrm{Ca}(\mathrm{OH})_{2}(\mathrm{~s})+\mathrm{MgCl}_{2}(\mathrm{aq})=\mathrm{Mg}(\mathrm{OH})_{2}(\mathrm{~s})+\mathrm{CaCl}_{2}(\mathrm{aq}) \\
\mathrm{C}-\mathrm{S}-\mathrm{H}(\mathrm{s})+\mathrm{MgCl}_{2}(\mathrm{aq}) \rightarrow \mathrm{M}-\mathrm{S}-\mathrm{H}(\mathrm{s})+\mathrm{CaCl}_{2}(\mathrm{aq}) \\
3 \mathrm{Ca}(\mathrm{OH})_{2}(\mathrm{~s})+\mathrm{CaCl}_{2}(\mathrm{aq})+12 \mathrm{H}_{2} \mathrm{O}(\mathrm{aq}) \rightleftharpoons 3 \mathrm{CaO} \cdot \mathrm{CaCl}_{2} \cdot 15 \mathrm{H}_{2} \mathrm{O}(\mathrm{s})
\end{gathered}
$$

37 The reactions associated with $\mathrm{MgCl}_{2}$ in Eq. 1 and 2 generally occur at the exposure surface since the 38 formation of insoluble brucite blocks the pathway for further ingress $[9,10,7]$. The pore-blocking 39 phenomenon leads to substantially lower chloride penetration depth in concrete exposed to $\mathrm{MgCl}_{2}$ solutions compared to that exposed to $\mathrm{NaCl}$ solutions [11].

41 The formation of Ca-Oxy shown in Eq. 3 is expansive [12], which builds up internal stress to cause damage 42 from cracking and microcracking [8]. Pioneering research on the damage to concrete due of Ca-Oxy 43 formation dates back to the 1970s [12], and this topic was discussed in some detail in two recent review 44 papers $[13,14]$. However, very few studies have clearly shown Ca-Oxy crystals formed in field concrete; 45 this is likely due to its thermodynamic instability and its tendency to break down during the carbonation 46 process [15]. The $\mathrm{Ca}(\mathrm{OH})_{2}-\mathrm{CaCl}_{2}-\mathrm{H}_{2} \mathrm{O}$ phase diagram illustrates the reversible nature of Ca-Oxy formation $47[12,16]$. Because Ca-Oxy is prone to decompose as the ambient temperature increases, it is extremely 48 difficult to preserve Ca-Oxy in cores or other samples of field concrete after winter or after they are removed 49 from cold environments. Peterson et al. [15] hypothesized a decomposition path from Ca-Oxy to calcite to 50 explain the lack of convincing field evidence of Ca-Oxy associated damage in pavements exposed to 51 significant deicers. 
In this work, we provide further insights into Ca-Oxy associated damage in field and lab specimens using microscopic methods. As a concrete petrography method, fluorescence microscopy (FM) has been implemented to quantify damage over the last three decades [17,18]. Reliable crack quantification by FM depends heavily on two aspects: (a) the fluorescent dye should be uniformly and thoroughly introduced and dispersed along all cracks and microcracks; and (b) the fluorescent dye should be only retained in cracks and microcracks on the examined surface [18]. The first aspect is realized by proper impregnation of florescent dye in resin or organic solute such as ethanol [17]. The second aspect is assured by proper polishing after impregnation [18]. Multiple algorithms and tools have been applied for quantitative crack analysis after obtaining the images [18-20], however, little research has focused on performing crack detection and quantification using well-developed tools such as ImageJ that have been widely used for biological and medical research [21]. In addition to contrast enhancement for crack detection, FM shows the potential to illustrate the capillary porosity in the cement paste matrix of concrete $[22,23]$. One important application is to determine water to cement ratio (w/c) [23]. More generally, the sensitivity of fluorescent light intensity on capillary porosity makes it an indicator of the microstructural alteration along the depth in cementitious materials subject to chemical attacks such as microbially induced corrosion [24].

Optical microscopy (OM) and scanning electron microscopy (SEM) are also powerful tools to discover changes in chemistry and mineralogy when cementitious materials are exposed to chemically deleterious environments [22]. For instance, OM and SEM have been commonly used to diagnose alkali-silica reaction

71 in concrete, and characterize the mineral component of reactive aggregate and the chemical composition of 72 ASR gel $[25,26]$.

73 This paper uses OM and FM to detect cracking and microstructural mineralogical alteration in field and 74 lab-cast cementitious mortars due to freeze-thaw cycles and deicer application. ImageJ is used to quantify cracks/microcracks in the field mortar and compare cracking to that in the lab-cast mortar and paste. SEM coupled with energy dispersive X-ray spectrometry (SEM-EDX) is used to characterize the morphology of secondary deposits and analyze their elemental compositions in the damaged field and lab-cast mortars. 
Image analysis is also performed on photomicrographs of thin sections to quantitively investigate the

79 leaching of $\mathrm{Ca}(\mathrm{OH})_{2}$ due to deicer application.

\section{2. Materials and experimental methods}

\section{$81 \quad 2.1$ Materials}

\section{$82 \quad$ 2.1.1 Field mortars}

83 The studied field mortar samples were obtained from substrate slabs that were designed to support tactile

84 warning tiles at a public transit facility in the Rocky Mountain Region of the US. The substrate slabs were 85 placed in 2014 and samples were obtained in 2020 after the slabs had been in service for six winter seasons.

86 Fig. 1 shows the average annual snowfall accumulation in the contiguous US (US National Oceanic and

87 Atmospheric Administration: https://www.noaa.gov). The average annual snowfall in the region where the samples are from is in the range of $122-182 \mathrm{~cm}$, and the exterior slabs were subject to frequent freeze-thaw cycles in winter. A deicer primarily consisting of $\mathrm{CaCl}_{2}$ was reportedly used in the first two winter seasons, while a deicer primarily consisting of $\mathrm{MgCl}_{2}$ was reportedly used in the following four winter seasons.

91 Two mortar samples designated as "undamaged field mortar" and "damaged field mortar" are shown in Fig.

92 2. The hard and compact undamaged field mortar was obtained from a relatively dry sheltered corner that

93 did not see significant deicer application. The friable damaged field mortar was obtained from a wet

94 unsheltered zone with significant deicer exposure. Both samples were fragmented during sampling. The 95 damaged field mortar shows white secondary deposits on the fragment surface. Although the exact mixture 96 design remains unknown, petrographic examinations indicate that the mortar samples are non-air-entrained 97 and do not contain any supplementary cementitious materials (SCMs). The damaged field mortar has had 98 long-term contact with deicer solutions through the edge of the tiles, considering the top surface of the 99 substrate slab is lower than the surrounding platform. 

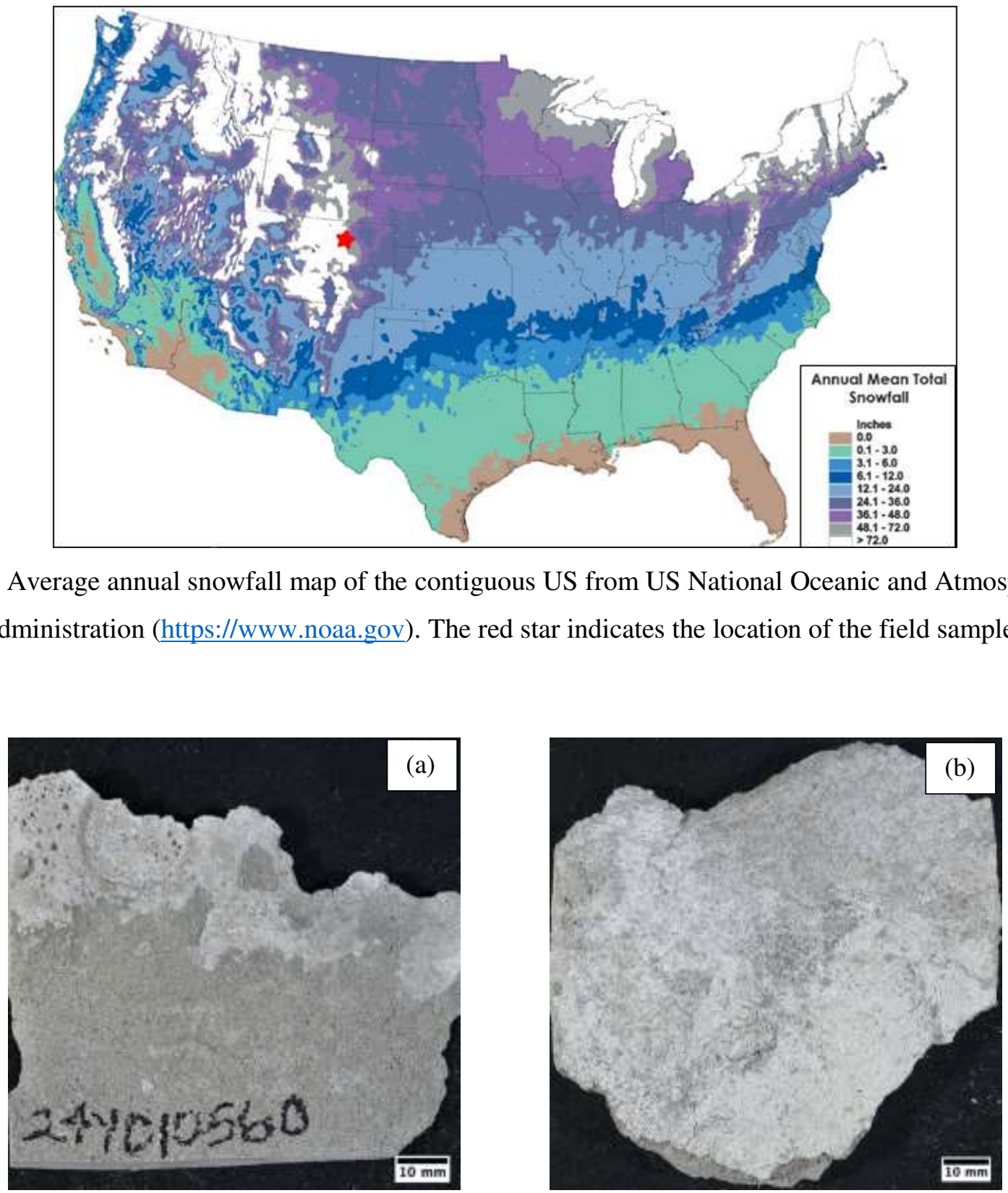

Fig. 1 Average annual snowfall map of the contiguous US from US National Oceanic and Atmospheric Administration (https://www.noaa.gov). The red star indicates the location of the field samples.

Fig. 2 The conditions of the as-received fragments of the undamaged field mortar (a) and the damaged field mortar (b), respectively.

109 Type I/II OPC was used to prepare an OPC paste and mortar in the lab for the comparative study with the

110 field mortar. The fine aggregate was a siliceous sand with a nominal maximum size of $4.75 \mathrm{~mm}$ and an 111 absorption of $2.84 \%$. Aggregates were corrected for water content before mixing. The OPC paste (P1) and 
112 mortar (M1) were mixed using a water-to-cement ratio (w/c) of 0.40; the mortar had a sand-to-cement ratio

113 of 2.0. The mixtures P1 and M1 were mixed using a benchtop mixer following ASTM C305, cast into 50-

$114 \mathrm{~mm}$ cubes and then cured in a moist room at $23{ }^{\circ} \mathrm{C}$ for 28 days.

\section{$115 \quad 2.2 .3 \mathrm{CaCl}_{2}$ solution}

116 Since the damage induced by $\mathrm{MgCl}_{2}$ is limited to a shallow zone next to the exposure surface [7], the lab-

117 cast $\mathrm{P} 1$ and $\mathrm{M} 1$ were only exposed to a $\mathrm{CaCl}_{2}$ solution during freeze-thaw cycles to mimic the damage by

$118 \mathrm{CaCl}_{2}$ in the field. A commercial deicer $\mathrm{CaCl}_{2}$ with a purity $>95$ wt. $\%$ was used to prepare solutions with

$119 \mathrm{a} \mathrm{CaCl}_{2}$ concentration of $25 \mathrm{wt}$ \% by mixing the salt with tap water in the appropriate weight proportions.

$120 \quad 2.2$ Experimental methods

121 2.2.1 Freeze-thaw cycles

122 At the age of 28 days, $\mathrm{P} 1$ and $\mathrm{M} 1$ were submerged in $25 \mathrm{wt} \% \mathrm{CaCl}_{2}$ solutions (liquid/solid ratio 0.7) in a

123 sealed container and then moved into a freezer for 24 hours. Temperature was monitored in areas around

124 the specimens during the 24-hour period; the recorded minimal temperature was $-8 \pm 1{ }^{\circ} \mathrm{C}$, which is

125 comparable to the average low temperature at the studied field location during the winter. After 24 hours

126 in the freezer, the container was removed from the freezer and kept under ambient conditions $\left(25 \pm 1{ }^{\circ} \mathrm{C}\right)$

127 for 24 hours, after which the procedure was repeated. Thus, each freeze-thaw cycle lasted 48 hours.

128 Although the ambient temperature was below $0{ }^{\circ} \mathrm{C}$ for 24 hours during each freezing stage, the specimen

129 temperature remained below $0{ }^{\circ} \mathrm{C}$ for only about 7 hours. Considering the high $\mathrm{CaCl}_{2}$ concentration of the

130 submersion solution, it is unlikely that actual freezing occurred.

131 Fine cracks (minor damage) were initially detected on the edges of P1 cubes after eight freeze-thaw cycles

132 and the specimen disintegrated completely after 51 cycles (failure). Fine cracks were observed in M1 after

133 seven cycles; M1 became friable and exhibited signs of severe damage (significant spalling and swelling)

134 after 53 cycles and disintegrated completely after 142 cycles (failure). Specimens were collected for

135 petrographic examinations after disintegration (51 cycles for P1 and 142 cycles for M1). 

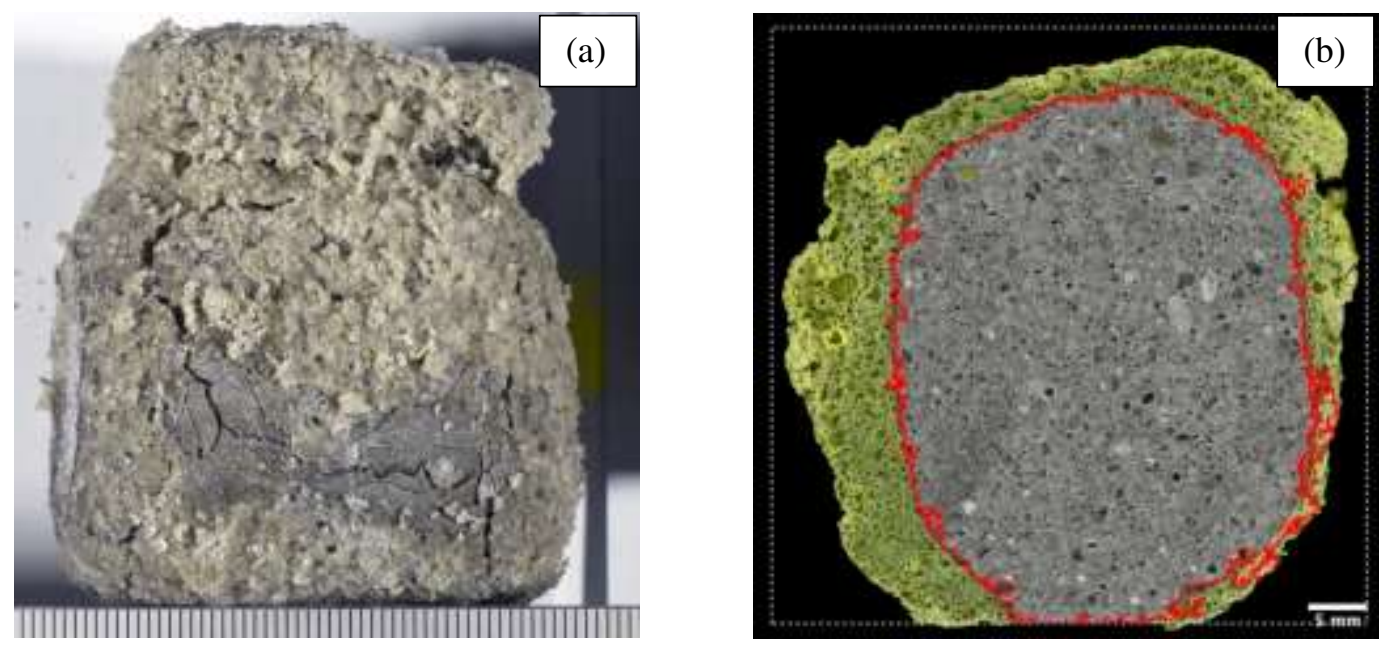

Fig. 3 (a) Photograph showing condition of the lab-cast mortar after 51 freeze-thaw cycles under the submersion of a 25 wt. $\% \mathrm{CaCl}_{2}$ solution. Scale in millimeters. (b) Reflected light photomicrograph of the polished surface of the lab-cast mortar. White square and red curve indicate the original size and the remaining intact zone of the sample, respectively. The yellow green color in (b) indicates the epoxied damage zone.

\subsubsection{Optical microscopy (OM)}

Optical microscopy was conducted on a polished slab and a thin section that represents a longitudinal cross section of each mortar sample (two field mortars and one lab-cast mortar) according to ASTM C856-20 [27]. Epoxy that contains fluorescent dye was used to stabilize the damaged field and lab-cast mortars prior to the polished slab preparation. Thin sections of all samples were impregnated with an epoxy containing fluorescent dye and ground and polished to a thickness of 20-25 $\mu \mathrm{m}$ by an automatic thin section machine (PELCON). A stereomicroscope (Nikon $\left.{ }^{\mathrm{TM}} \mathrm{SMZ}-25\right)$ and a petrographic microscope (Nikon ${ }^{\mathrm{TM}}$ E-Pol 600) were used to examine the polished slabs and thin sections, respectively.

\subsubsection{Scanning electron microscopy coupled with energy dispersive X-ray spectrometry (SEM-EDX)}

A scanning electron microscope (FEITM Quanta 250) coupled with an energy dispersive X-ray (EDX, Thermo Scientific ${ }^{\mathrm{TM}}$ UltraDry EDS) was used to examine the morphology and elemental compositions of secondary deposits that line cracks, microcracks and voids in the samples. Uncoated fracture surfaces of each sample were examined in the low vacuum ( $70 \mathrm{~Pa})$ mode using an accelerating voltage of $15 \mathrm{kV}$ at a working distance of $10 \mathrm{~mm}$. 


\section{Damage quantification}

157 Fig. 4 shows the cracking patterns in the damaged field mortar, lab-cast mortar and paste after exposure to 158 freeze-thaw cycles and deicers. Each sample exhibits a network of interconnected cracks $(0.1-1 \mathrm{~mm}$ in 159 width) and microcracks ( $<0.1 \mathrm{~mm}$ in width). The cracks and microcracks are subparallel to the exposure

160 surface and cut around aggregate particles, which consist mostly of quartz grains. Without the restraint 161 imposed by fine aggregate particles, the cracks in the lab-cast paste P1 are parallel to each other, and each 162 delamination sheet in P1 has approximately the same thickness of $200 \pm 25 \mu \mathrm{m}$. These characteristics are 163 typical of damaged observed from freeze-thaw cycles [22].

164 Secondary deposits were observed to fill cracks and microcracks near the exposed surface in each sample, 165 as shown in Fig. 4a, 4c and 4f. This is consistent with the formation of Ca-Oxy due to the application of $166 \mathrm{CaCl}_{2}$ [15]. The secondary deposits are white and translucent on the polished surface of two mortars (in 167 Fig. 4a and 4c), while they are transparent on the fresh surface of the delamination sheet in the paste (in 168 Fig. 4f). The difference in appearance is likely related to drying effects during the preparation of the 169 polished surface [15].

170 Fig. 5a-5d show bright green cracks/microcracks that are filled with epoxy containing fluorescent dye under 171 the ultraviolent light. Since very little epoxy is able to penetrate the paste from the cracks/microcracks, the 172 paste matrix and aggregate are dark green to black as background. This enhanced contrast between the 173 cracks/microcracks and matrix affords an opportunity to quantify cracking through image analysis. Cracks

174 and microcracks can be automatically recognized and extracted on the polished surfaces using a plugin 175 "Ridge Detection" in ImageJ [28], as illustrated in Fig. 5e-5h. The "Ridge Detection" plugin requires three 176 parameters: (a) line width; (b) highest grayscale value of the line; and (c) lowest grayscale value of the line. 177 After several trials, the values of the three parameters were determined as 15 pixels, 255 and 80, respectively, 178 for the best detection. The above process output three important parameters regarding the cracking 179 characteristics, i.e., the length, mean width and orientation of each crack/microcrack.

180 As geometric features of a partially connected crack network, the orientations of cracks/microcracks are 181 closely related to the fracture process and progress in solids [20]. Fig 5i-51 show rose diagrams of 
182

183

184

185

186

187

188

189

190

191

192

193

194

195

196

crack/microcrack orientations at different depths in the damaged field and lab-cast mortars. The statistical data of cracking orientations further confirms the preferred cracking direction that tends to be parallel to the exposure surface of both field and lab-cast mortars. There is a variation of $30-45^{\circ}$ in the preferred orientation due to the constraints of sand particles in the mortar.

Cracking length and mean width are direct measures of the extent of material damage. They are used to calculate crack density $\left(l, \mathrm{~mm} / \mathrm{mm}^{2}\right)$ and crack area fraction ( $s$, unitless) as follows:

$$
\begin{aligned}
& l=\frac{\sum L_{\text {crack }}}{S S} \\
& S=\frac{\sum L_{\text {crack }} \cdot W_{\text {crack }}}{S S}
\end{aligned}
$$

where, $L_{\text {crack }}(\mathrm{mm})$ and $W_{\text {crack }}\left(\mathrm{mm}^{2}\right)$ are the length and mean width of a crack/microcrack in the selected zone with an area of $S S\left(\mathrm{~mm}^{2}\right)$. Although somewhat differing definitions of crack density have been adopted in previous studies [18,20], this paper uses Eq. 4 to define the crack density for the following discussion. Fig. 6 summarizes the measured results in randomly selected zones (Fig. 5) at two different depths of each damaged mortar. In both damaged mortars, the area further from the exposure surface shows a lower crack density and area fraction, which indicates the progression of damage with depth. It is impossible to obtain the absolute depth of the selected zones since the original exposure surface had been missing due to severe damage. Compared to the damaged field mortar, the lab-cast mortar shows approximately 3-4 times higher crack density and 1-3 times higher crack area percentage, indicating more damage occurred under the accelerated exposure conditions realized in the laboratory. The phase diagram for the $\mathrm{Ca}(\mathrm{OH})_{2}-\mathrm{CaCl}_{2}-\mathrm{H}_{2} \mathrm{O}$ system demonstrates that $\mathrm{Ca}-\mathrm{Oxy}$ is a stable phase in a $25 \mathrm{wt} . \% \mathrm{CaCl}_{2}$ solution at a temperature lower than $40{ }^{\circ} \mathrm{C}$ [29]. This implies that the formed Ca-Oxy was able to constantly damage the lab-cast mortar throughout each freeze-thaw cycle $\left(-8{ }^{\circ} \mathrm{C}\right.$ to $\left.25^{\circ} \mathrm{C}\right)$. In the field, external factors, such as loss of the deicer solutions from drainage and dilution of these solutions from rainfall, reduce the potential for Ca-Oxy to be a stable phase. Additional Ca-Oxy destabilization also occurs from carbonation, which is minimized in the lab due to constant submersion in the deicer solution. [15]. 

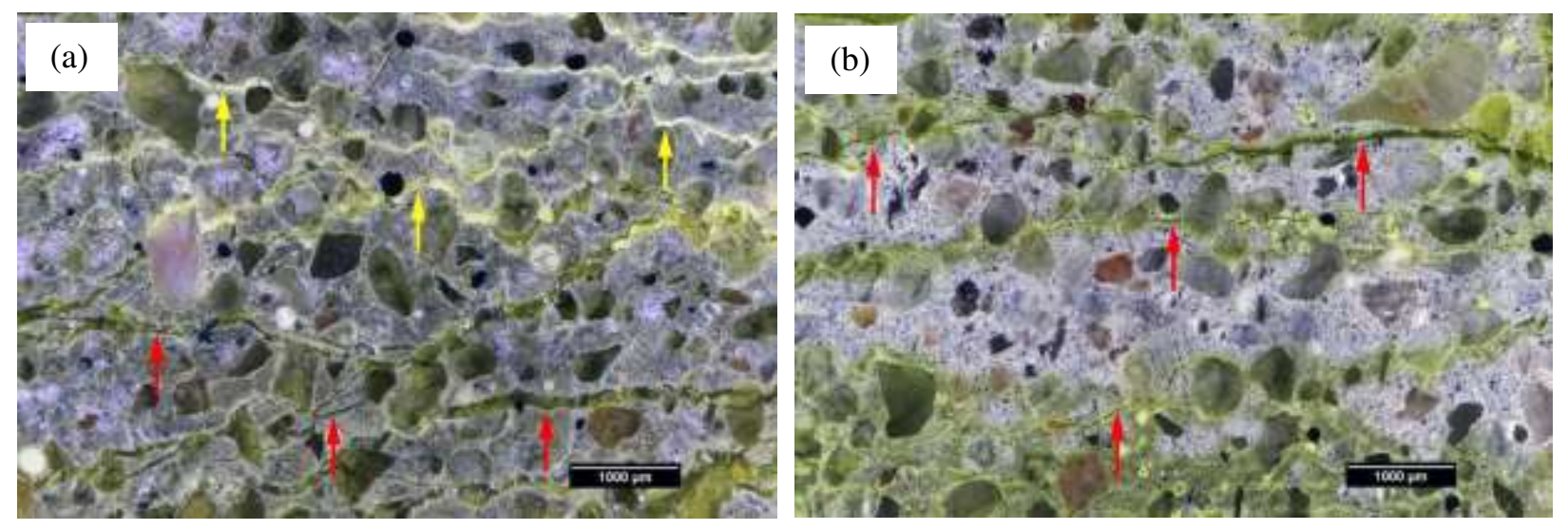

207
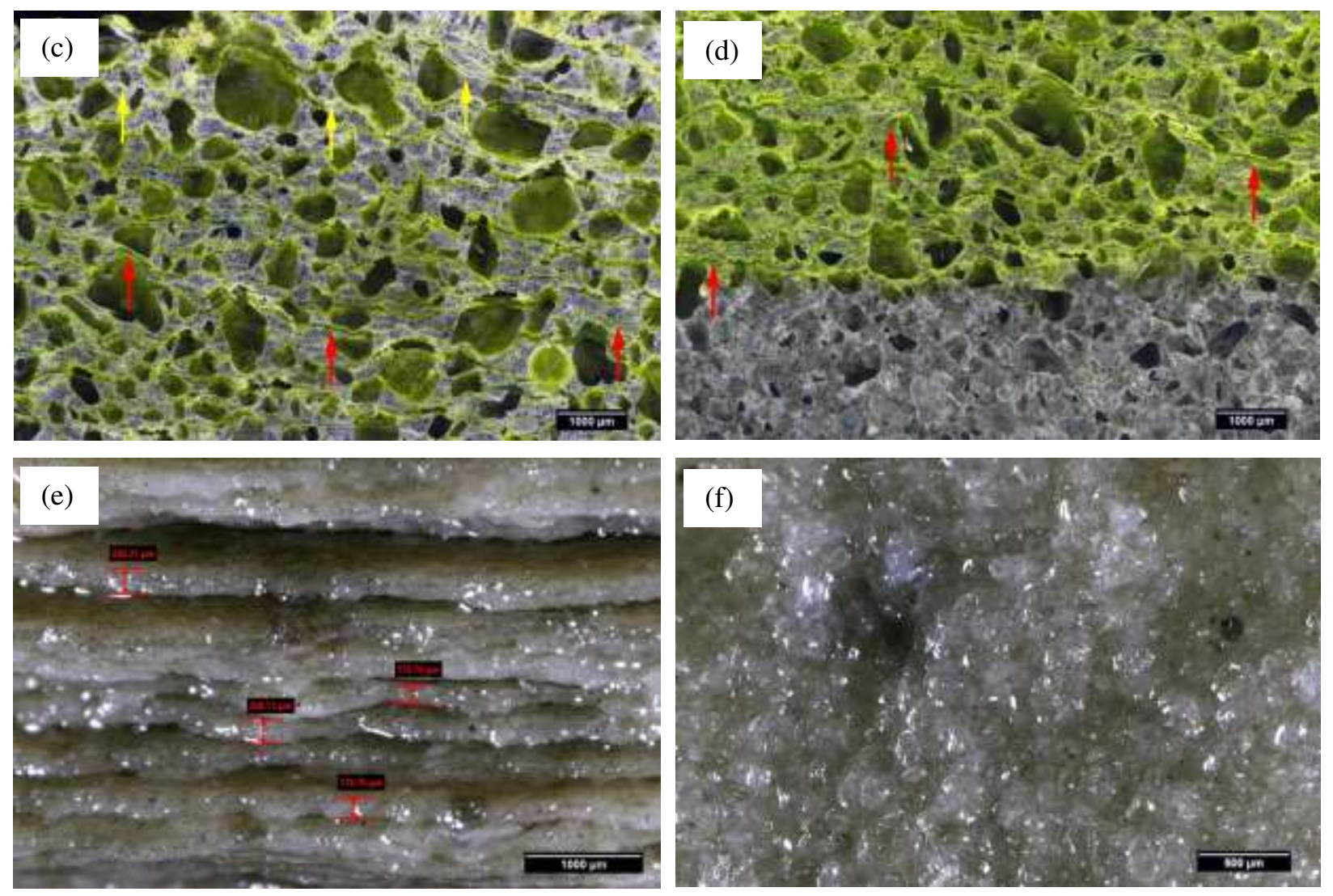

Fig. 4 (a)-(d) Reflected light photomicrographs (RLP) of the polished surface of the damaged field mortar

210 (a-b) and lab-cast mortar (c-d) showing horizontal cracks/microcracks at two different depths from the

211 exposure surface, respectively. Zones in (a) and (c) are closer to the exposure surface. Yellow and red

212 arrows indicate cracks/microcracks with and without secondary deposits, respectively. (e) Fresh

213 delamination sheets in the damaged lab-cast paste. (f) Transparent secondary deposits on the surface of

214 the delamination sheet in (e). 

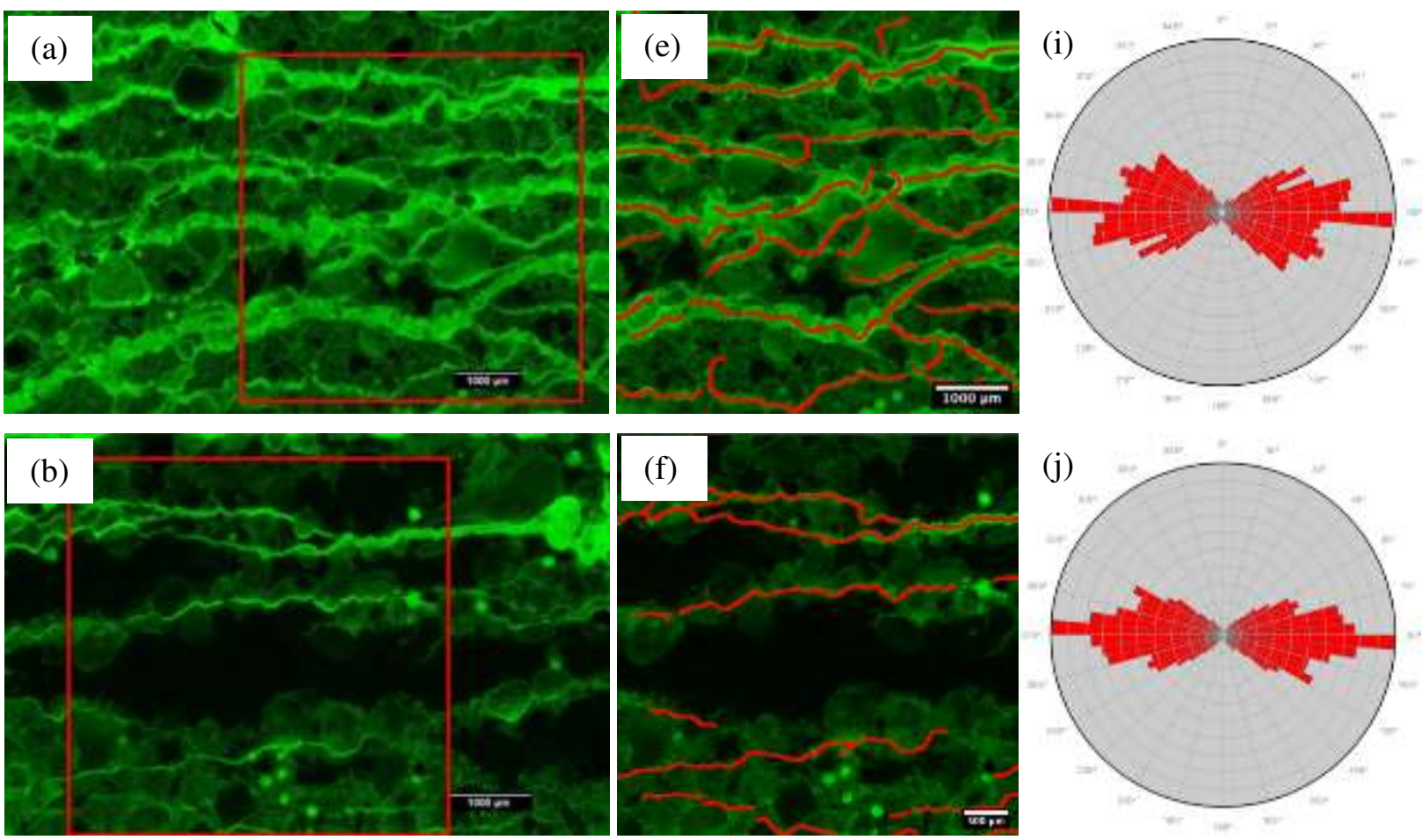

216
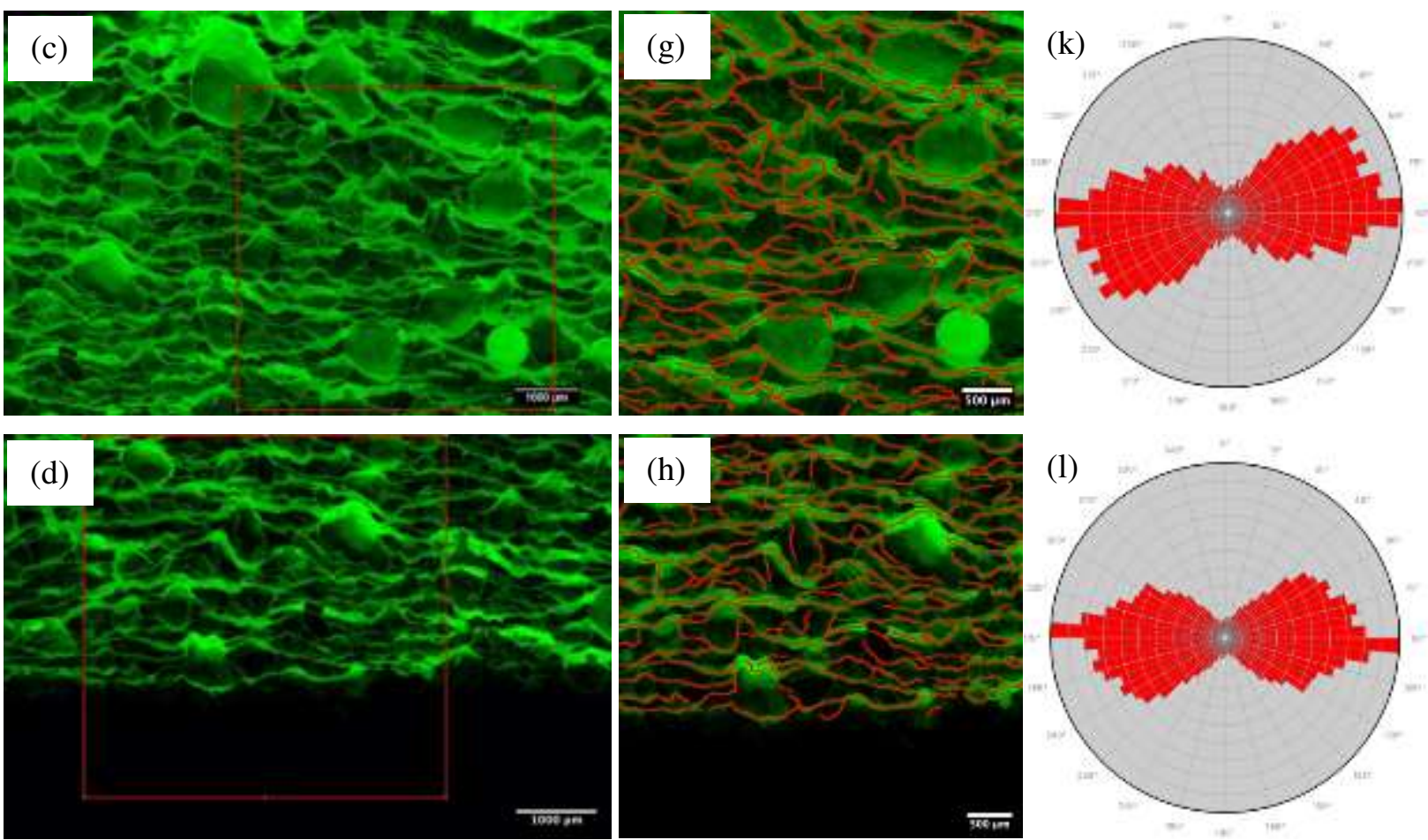

Fig. 5 (a)-(b) Fluorescent reflected light photomicrographs (FRLP) of the polished surface of the

220 damaged field mortar showing cracks/microcracks in the upper and lower zones from the top surface,

221 respectively. (c)-(d) FRLP of the polished surface of the lab-cast mortar showing cracks/microcracks in

222 the closer (outward) and further (inward) zones from the outer surface, respectively. (e)-(h) Identified

223 crack network in the red zone in (a)-(d). (i)-(l) Rose diagrams showing the cracking orientation in (e)-(h). 


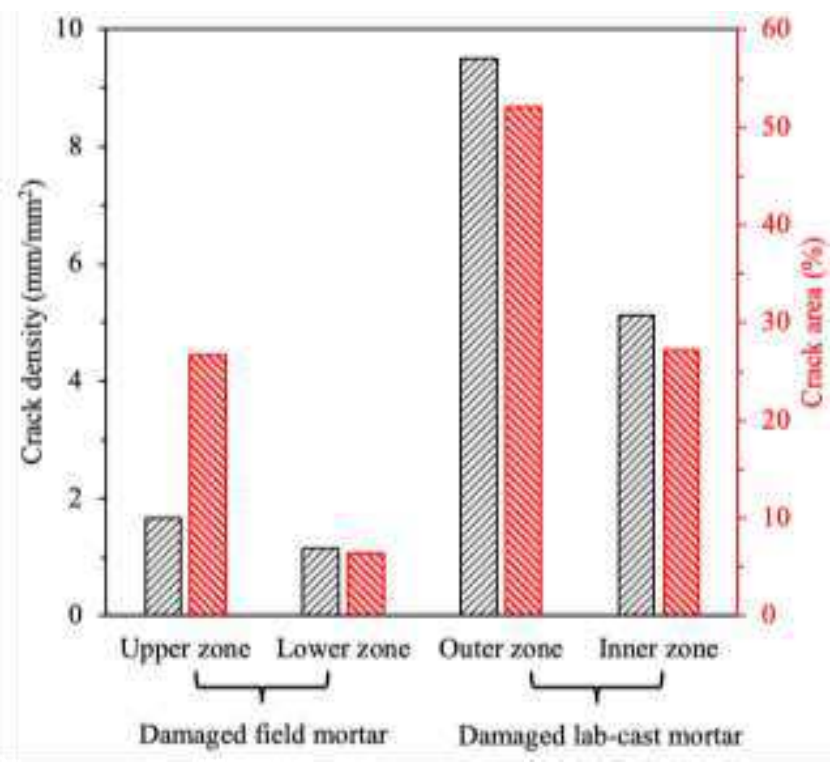

Fig. 6 Crack density (left series) and crack area fraction (right series) in different zones of the field damaged field mortar and lab-cast mortar.

\section{Mineralogical alteration quantification}

\subsection{Secondary deposits}

SEM-EDX was used to examine the secondary deposits observed in the damaged field mortar and lab-cast paste after exposure to $\mathrm{CaCl}_{2}$ deicer solutions. To avoid the chemical and physical alteration of secondary deposits during sample preparation, only fresh fracture surfaces of each sample were examined. Fig. 7 shows the morphology of secondary deposits in different locations of the damaged field mortar. Although a well-polished surface renders EDX semi-quantitative analyses at best, one can still recognize the elemental composition of phases of interest on fracture surfaces. Multiple secondary deposits were observed in the damaged field mortar as follows:

(a) Friedel's salt. As the external chloride ions penetrate the cement-based mortar, they react with calcium monosulfoalunimate (AFm) and its iron analog to form Friedel's salt [30], which is distributed in the paste matrix in Fig. 7a.

(b) Ettringite. Clusters of fibrous secondary ettringite were observed filling air voids, as shown in Fig.

7b. The conversion of AFm to Friedel's salt by ionic exchange releases sulfate ions, which can further react with the remaining AFm to form secondary ettringite [31,32]. The presence of external 
deicers in the pore solution leads to a relatively high internal humidity in the mortar, and this helps stabilize ettringite that has a high water content $\left(32 \mathrm{H}_{2} \mathrm{O}\right.$ molecules) [33].

(c) Ca-Oxy. Ca-Oxy forms when $\mathrm{CaCl}_{2}$ deicer reacts with $\mathrm{Ca}(\mathrm{OH})_{2}$ in the cement paste (Eq. 3). CaOxy manifests as prismatic crystals that were observed filling air voids and lining cracks/microcracks in Fig. 7b-7c. This is consistent with previous observations by Galan et al. [34]. The Ca-Oxy crystals exhibit a series of developed microcracks parallel to the prism axis, which may be related to partial dehydration of the crystals in the SEM vacuum chamber [34].

250 The observed secondary deposits were chemically analyzed and verified using EDX in Fig. 7d, which shows 251 that they have comparable elemental ratios to the corresponding theoretical formulas. No evidence of 252 significant deposits of brucite or M-S-H was observed within in the damaged field mortar. This is consistent 253 with brucite blocking pores at the exposure surface [11,7].

254 The sensitivity of Ca-Oxy morphology to drying is further investigated in the lab-cast paste P1. Fig. 8 shows the different Ca-Oxy crystals that are freshly obtained from P1 and vacuum dried in the SEM chamber at a vacuum level of $\sim 70 \mathrm{~Pa}$ for 12 hours. Compared to the fresh Ca-Oxy crystals, the dried Ca-Oxy crystals

257 become white and translucent to opaque (Fig. 8a-8b), which is related to the white secondary deposits filling cracks/microcracks on the polished surfaces of mortars in Fig. 4a and 4c. Moreover, the dried Ca-Oxy 259 prisms shrank and further cracked due to the loss of water, as shown in Fig. 8c-8d. This is consistent with 260 previously reported observations [34]. EDX analysis in Fig. 8e-8f shows that the majority of dried Ca-Oxy 261 crystals maintain the same elemental composition as the fresh Ca-Oxy crystals. However, a portion of dried 262 Ca-Oxy crystals may have been converted to a type of calcium oxychloride without water, e.g. $263 \mathrm{Ca}(\mathrm{OH})_{2} \cdot \mathrm{CaCl}_{2}$, as shown in Fig. 8f. 

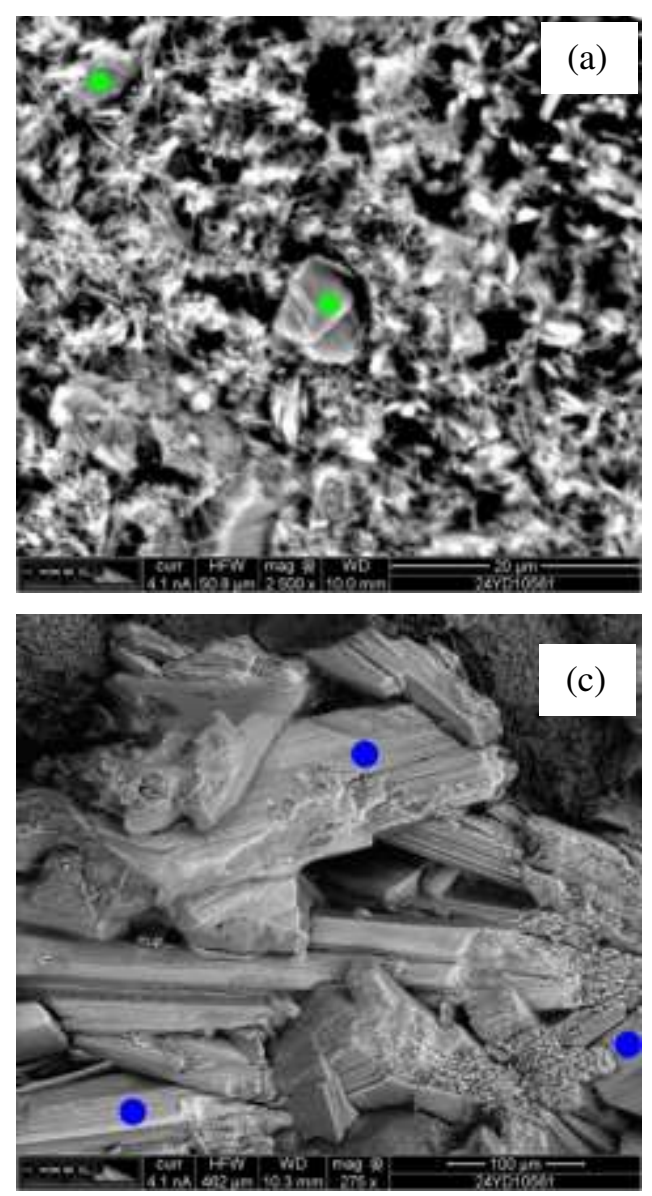
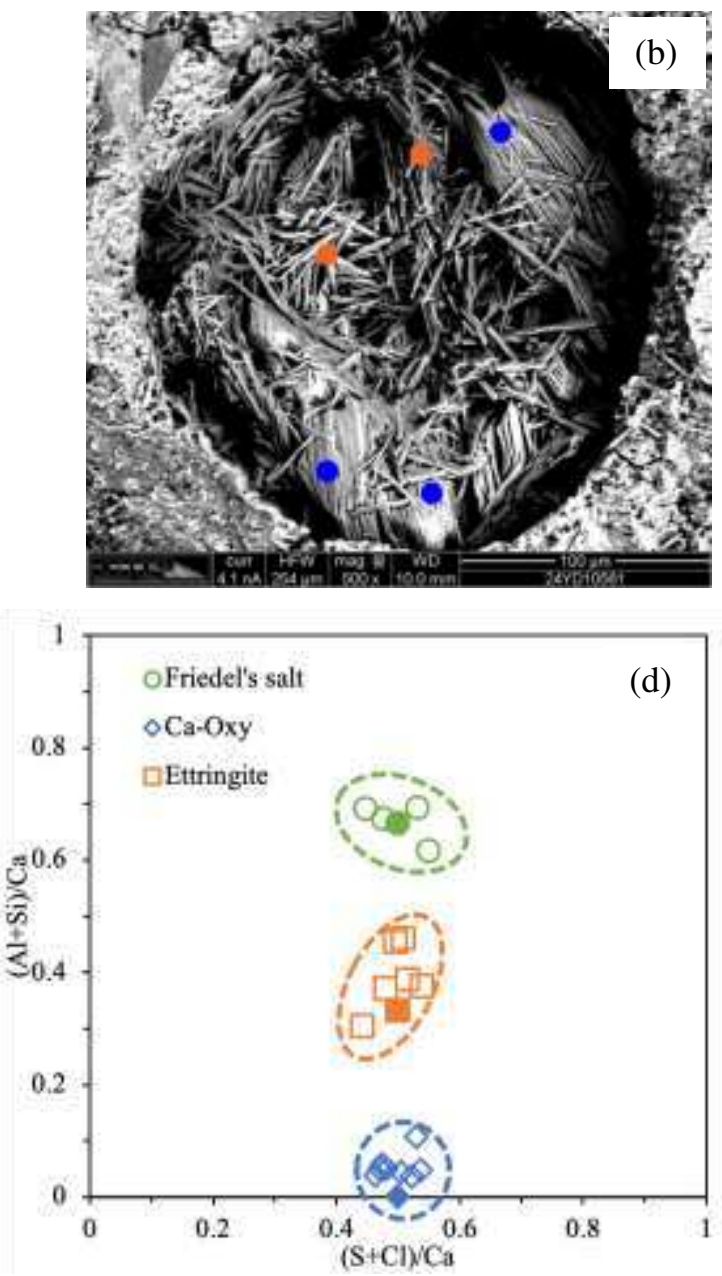

264 Fig. 7 (a)-(c) Backscattered electron (BSE) images of secondary deposits in (a) the paste matrix, (b) an 265 entrained air void and (c) a fresh fracture surface, respectively. Green circles: Friedel's salt, blue 266 diamonds: Ca-Oxy; orange squares: ettringite. (d) Atomic ratios obtained from EDX spectra in zones in (a)-(c). The solid shapes indicate the theoretical composition of the corresponding minerals. 

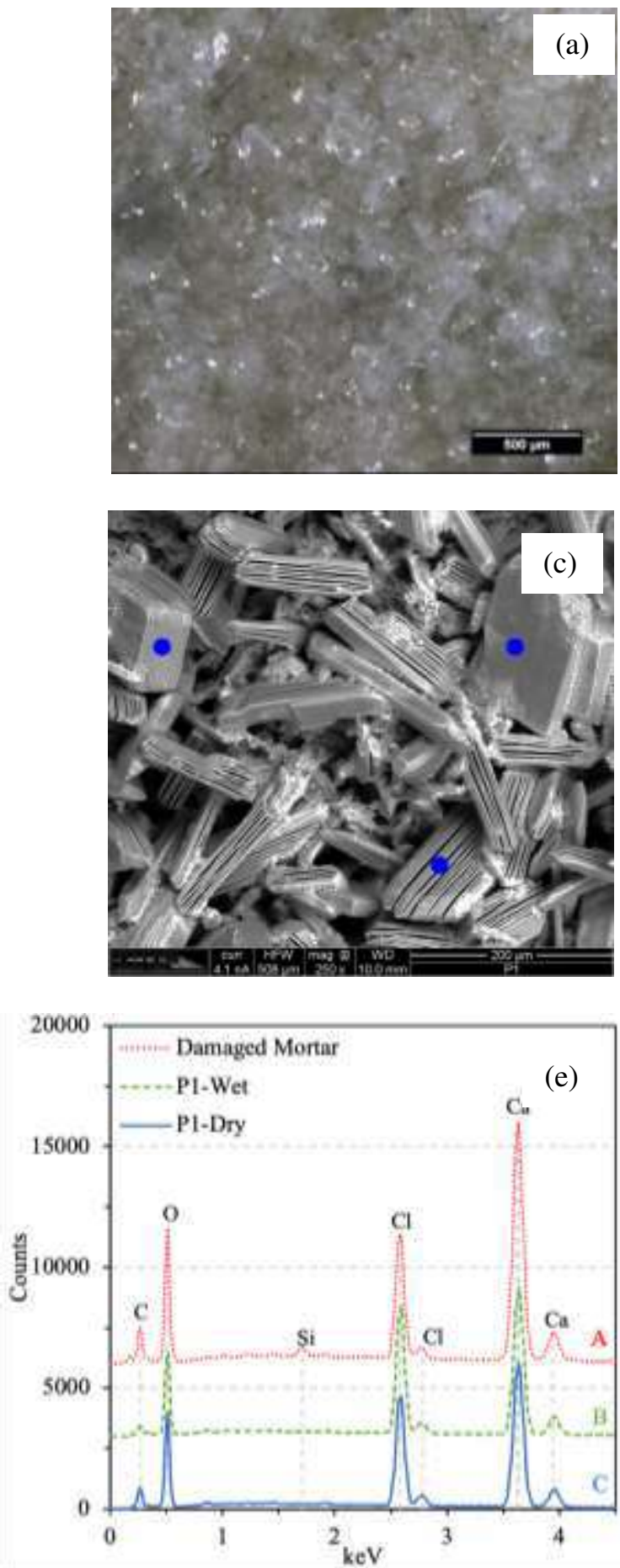
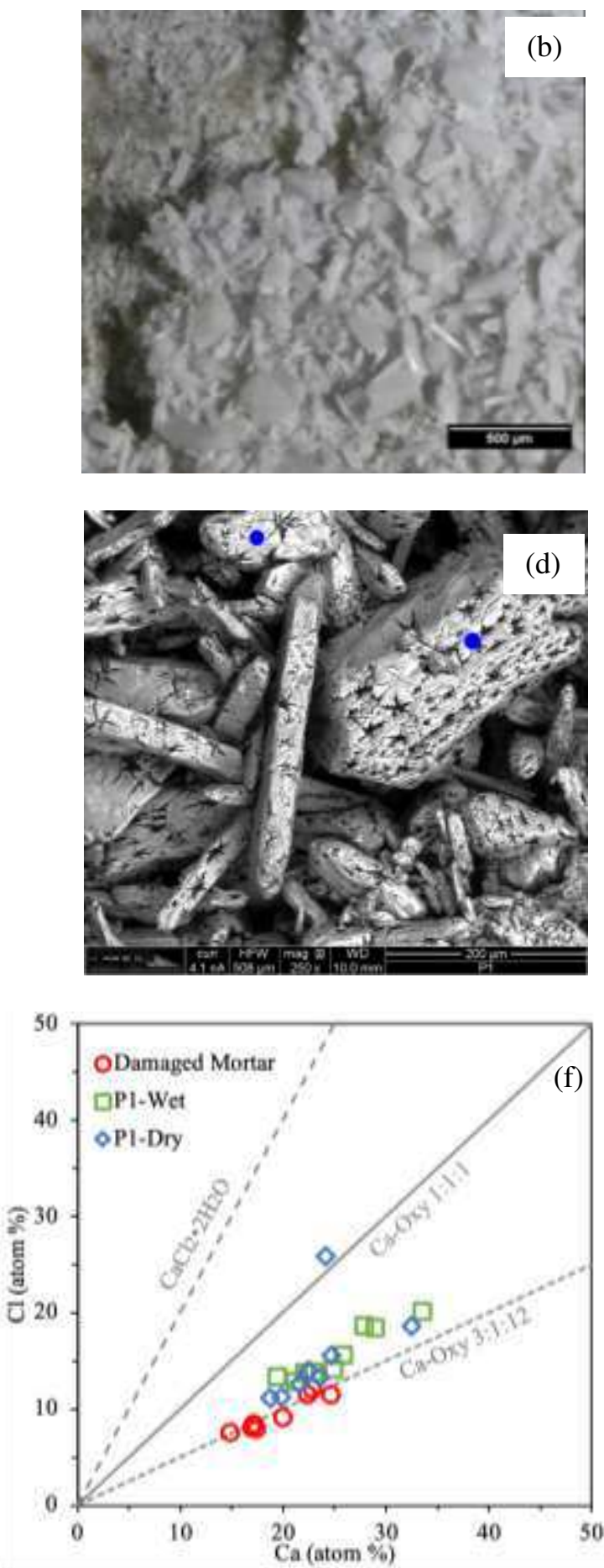

Fig. 8 (a)-(b) RLP and (c)-(d) BSE images of Ca-Oxy (blue solid dots) in (a)/(c) an originally wet

272 condition and (b)/(d) a dried condition on a fracture surface of OPC paste, respectively. (e) EDX spectra

273 obtained from zones in Fig. 5c and Fig. 6a-6b. (f) Relationship between $\mathrm{Ca}$ and $\mathrm{Cl}$ contents of Ca-Oxy 


\section{2 $\mathrm{Ca}(\mathrm{OH})_{2}$ leaching}

277 Fig. 9 highlights $\mathrm{Ca}(\mathrm{OH})_{2}$ present in the undamaged and damaged field mortars via transmitted cross278 polarized light microscopy with the first order retardation plate. The $\mathrm{Ca}(\mathrm{OH})_{2}$ crystals are in first order 279 yellow and second order blue interference colors. The undamaged field mortar shows $\mathrm{Ca}(\mathrm{OH})_{2}$ crystals 280 evenly distributed in the paste matrix, while $\mathrm{Ca}(\mathrm{OH})_{2}$ crystals are scarce in the damaged field mortar paste.

281 This finding directly confirms that the deicer application, especially $\mathrm{CaCl}_{2}$, can lead to the leaching of $282 \mathrm{Ca}(\mathrm{OH})_{2}$ in the field due the formation of Ca-Oxy [32,7]. $\mathrm{MgCl}_{2}$ deicer can also consume $\mathrm{Ca}(\mathrm{OH})_{2}$ due to 283 the formation of brucite, but its influence is limited in areas adjacent to the exposure surface considering 284 the absence of brucite in the bulk of the examined samples.

285 Since $\mathrm{Ca}(\mathrm{OH})_{2}$ crystals show distinct colors from the other hydrates in the paste matrix in Fig. 9a and 9c, image segmentation can be performed to quantify the volume (area) fraction of $\mathrm{Ca}(\mathrm{OH})_{2}$ crystals in the paste matrix. Firstly, the aggregate particles were selected and excluded (green areas in Fig. 9b and 9d) manually in ImageJ before the segmentation. The remaining section in each image truly represents the paste matrix. Three classes of components are categorized as follows: (a) $\mathrm{Ca}(\mathrm{OH})_{2}$ crystals that are in in first order yellow and second order blue interference color; (b) the other hydrates that are in purple as

291 background; and (c) the unhydrated cement particles that are opaque in dark brown to black. The image segmentation were performed using the plugin "Trainable Weka Segmentation” in ImageJ [35]. This plugin provides pixel-based segmentation using multiple machine learning algorithms together with a set of selected image features. Three classes of pixels were defined based on the above three components in the paste. After different areas were selected and assigned to each class as inputs, the plugin automatically produces satisfactory segmentation after a few training instances, as shown in Fig. 9b and 9d. The zoomed

297 in areas in Fig. 9e-9h indicate that the machine learning based segmented areas agree well with the actual 298 corresponding components.

299 Fig. 10 plots the volumetric (area) fraction of $\mathrm{Ca}(\mathrm{OH})_{2}$ normalized to the total hydrates in the paste. 300 Compared to the undamaged field mortar, the damaged field mortar shows a significant reduction of $86.4 \%$ 301 in $\mathrm{Ca}(\mathrm{OH})_{2}$ based on the above image analysis. The analyzed $\mathrm{Ca}(\mathrm{OH})_{2}$ volumetric faction $(26.7 \%)$ in the 

the reliability and feasibility of applying optical microscopy coupled with image analysis to quantitively

304 investigate the chemical alteration caused by deicers. This methodology can be further extended to analyze

305 other durability-related microstructural alteration if a distinct feature can be defined under microscopes.

306
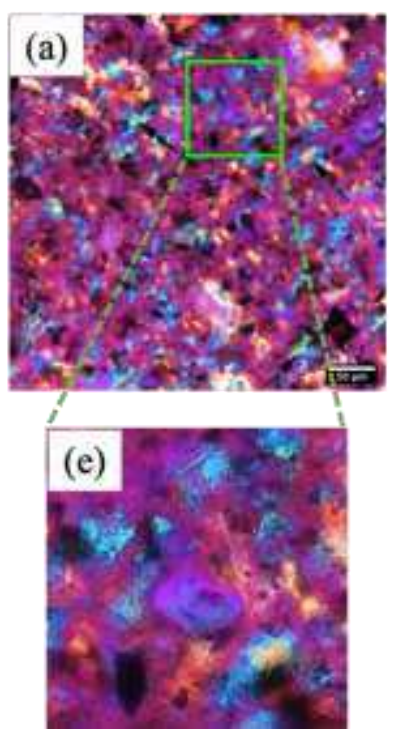
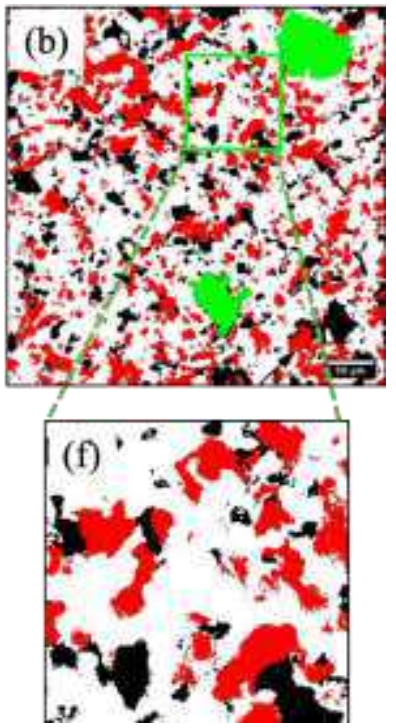
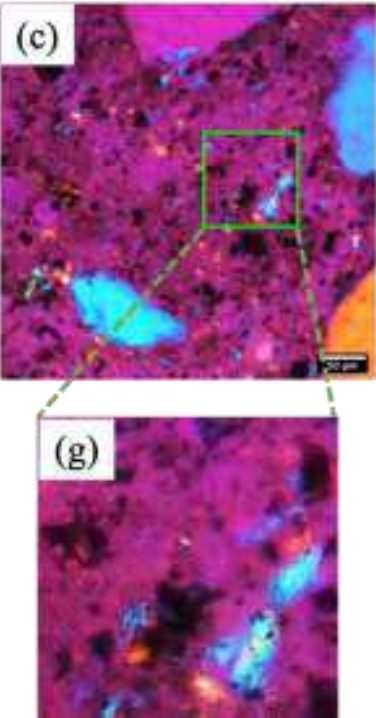
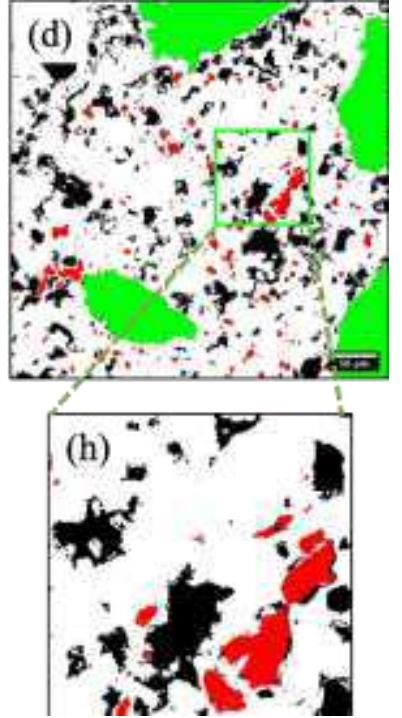

Fig. 9 (a)\&(c) Transmitted light photomicrographs showing paste in the middle of the (a) undamaged field mortar and (c) damaged field mortar, respectively, in cross-polarized light with the gypsum first order retardation plate inserted. (b)\&(d) Segmentation images of the photomicrographs in (a) and (c) using 2D Trainable Weka Segmentation in ImageJ [35]. (e)-(h) Zoomed-in images of the corresponding zones in (a)-(d). The size of the zone in (e)-(h) is $100 \mu \mathrm{m}$ by $100 \mu \mathrm{m}$.

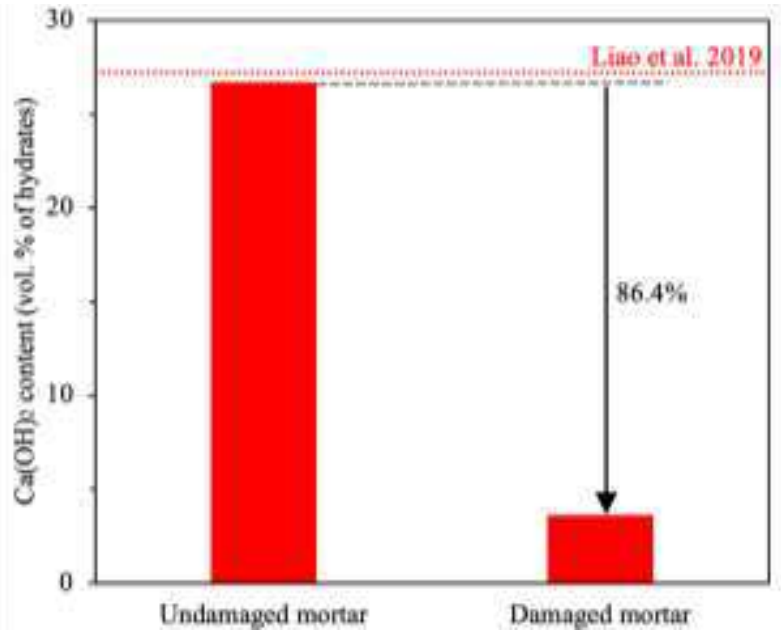

313 Fig. 10 Quantification of $\mathrm{Ca}(\mathrm{OH})_{2}$ contents in the mortars using image analysis. The red dotted line indicates the value from Ref. [36]. 


\section{Conclusions}

316 This paper demonstrates the utility of combining petrographic methods with image analysis to quantify

317 damage of cementitious materials exposed to freeze-thaw cycles and chloride-based deicers. The damaged

318 field and lab-cast mortars show similar cracking patterns including: (a) a network of interconnected

319 cracks/microcracks that are parallel to the exposure surface; and (b) lowered crack density over the depth.

320 Both damaged field and lab-cast mortars show a variation of $30-45^{\circ}$ in the preferred orientation due to the

321 constraints of sand particles. Compared to the damaged field mortar, the lab-cast mortar shows 3-4 times

322 higher crack density and 1-3 times higher crack area fraction because the accelerated lab exposure

323 conditions are far more severe than the field exposure conditions.

324 SEM-EDX analysis confirms the elemental compositions of three distinct secondary deposits: Friedel's salt,

325 ettringite and Ca-Oxy. The altered appearance of Ca-Oxy after drying demonstrates the influence of sample

326 preparation on the formed Ca-Oxy.

327 Transmitted cross-polarized light microscopy with the first order retardation plate can be used to perform

328 image segmentation and quantify the volume fraction of $\mathrm{Ca}(\mathrm{OH})_{2}$ in the cement-based materials. Compared

329 to the undamaged field mortar, the damaged field mortar shows a reduction of $86.4 \%$ in $\mathrm{Ca}(\mathrm{OH})_{2}$ content,

330 suggesting the significant leaching of $\mathrm{Ca}(\mathrm{OH})_{2}$ due to the formation of Ca-Oxy.

\section{Acknowledgements}

333 The authors gratefully thank the assistance of Mr. Gaines Green and Ms. Grace Guryan for sample 334 preparation at DRP, A Twining Company.

336 Authors' contribution

337 Chunyu Qiao: Conceptualization, Methodology, Investigation, Formal analysis, Resources, Writing 338 Original Draft, Supervision, Project administration.

339 Nima Hosseinzadeh Nanehkaran: Investigation, Resources, Review \& Editing.

340 Prannoy Suraneni: Investigation, Resources, Review \& Editing, Funding acquisition. 
Sihang Wei: Investigation, Review \& Editing.

342 David Rothstein: Investigation, Project administration, Review \& Editing.

\section{Funding}

345 Funding assistance from Ready Mixed Concrete Research and Education Foundation for the project "The

346 role of air content and supplementary cementitious materials replacement in deicing salt joint damage in

347 concrete" is acknowledged.

\section{Availability of data and materials}

350 Some or all data generated or used during the study are available from the corresponding author by request.

\section{Competing interests}

The authors declare that they have no competing interests.

\section{References}

1. Yehia S, Tuan CY Bridge deck deicing. In: Transportation Conference Proceedings, Iowa State University, Ames, 1998. pp 51-57.

358 2. Fischel M (2001) Evaluation of selected deicers based on a review of the literature CDOT-DTD-R-2001-15.

359 Colorado Department of Transportation, Denver.

360 3. Mussato BT, Gepraegs OK, Farnden G (2004) Relative effects of sodium chloride and magnesium chloride on

361 reinforced concrete: State of the art. Transportation Research Record 1866 (1):59-66.

362 doi:https://doi.org/10.3141/1866-08

363 4. Ramakrishna DM, Viraraghavan T (2005) Environmental Impact of Chemical Deicers - A Review. Water, Air, 364 and Soil Pollution 166 (1):49-63. doi:https://doi.org/10.1007/s11270-005-8265-9

365 5. Ababneh A, Benboudjema F, Xi YP (2003) Chloride penetration in nonsaturated concrete. Journal of Materials in 366 Civil Engineering 15 (2):183-191. doi:https://doi.org/10.1061/(Asce)0899-1561(2003)15:2(183)

367 6. Bastidas-Arteaga E, Chateauneuf A, S A Nchez-Silva M, Bressolette P, Schoefs F (2011) A comprehensive 368 probabilistic model of chloride ingress in unsaturated concrete. Eng Struct 33 (3):720-730.

369 doi:https://doi.org/10.1016/j.engstruct.2010.11.008

370 7. Qiao C, Suraneni P, Tsui Chang M, Weiss J (2018) Damage in cement pastes exposed to $\mathrm{MgCl}_{2}$ solutions.

371 Materials and Structures 51 (3):74. doi:https://doi.org/10.1617/s11527-018-1191-2 
8. Qiao C, Suraneni P, Weiss J (2018) Flexural strength reduction of cement pastes exposed to $\mathrm{CaCl}_{2}$ solutions. Cement and Concrete Composites 86:297-305. doi:https://doi.org/10.1016/j.cemconcomp.2017.11.021

9. Sutter L, Peterson K, Touton S, Van Dam T, Johnston D (2006) Petrographic evidence of calcium oxychloride formation in mortars exposed to magnesium chloride solution. Cement and Concrete Research 36 (8):1533-1541. doi:http://dx.doi.org/10.1016/j.cemconres.2006.05.022

10. Farnam Y, Wiese A, Bentz D, Davis J, Weiss J (2015) Damage development in cementitious materials exposed to magnesium chloride deicing salt. Construction and Building Materials 93:384-392.

doi:http://dx.doi.org/10.1016/j.conbuildmat.2015.06.004

11. Qiao C, Ni W, Wang Q, Weiss J (2018) Chloride Diffusion and Wicking in Concrete Exposed to $\mathrm{NaCl}$ and $\mathrm{MgCl}_{2}$ Solutions. Journal of Materials in Civil Engineering 30 (3):04018015.

doi:http://dx.doi.org/10.1061/(ASCE)MT.1943-5533.0002192

12. Chatterji S (1978) Mechanism of the $\mathrm{CaCl}_{2}$ attack on Portland cement concrete. Cement and Concrete Research 8 (4):461-467. doi:http://dx.doi.org/10.1016/0008-8846(78)90026-1

13. Smith SH, Qiao C, Suraneni P, Kurtis KE, Weiss WJ (2019) Service-life of concrete in freeze-thaw environments: Critical degree of saturation and calcium oxychloride formation. Cement and Concrete Research 122:93-106. doi:https://doi.org/10.1016/j.cemconres.2019.04.014

14. Jones C, Ramanathan S, Suraneni P, Hale WM (2020) Calcium oxychloride: A critical review of the literature surrounding the formation, deterioration, testing procedures, and recommended mitigation techniques. Cement and Concrete Composites 113:103663. doi:https://doi.org/10.1016/j.cemconcomp.2020.103663

15. Peterson K, Julio-Betancourt G, Sutter L, Hooton RD, Johnston D (2013) Observations of chloride ingress and calcium oxychloride formation in laboratory concrete and mortar at $5^{\circ} \mathrm{C}$. Cement and Concrete Research 45:79-90. doi:https://doi.org/10.1016/j.cemconres.2013.01.001

16. Collepardi M, Coppola L, Pistolesi C Durability of concrete structures exposed to $\mathrm{CaCl}_{2}$ based deicing salts. In: Proceedings of the 3rd CANMENT/ACI International Conference, France, 1994. American Concrete Institute, Farmington Hills, MI, pp 107-120

17. Hornain H, Marchand J, Ammouche A, Commène JP, Moranville M (1996) Microscopic observation of cracks in concrete - A new sample preparation technique using dye impregnation. Cement and Concrete Research 26 (4):573-583. doi:https://doi.org/10.1016/0008-8846(96)00032-4

18. Ammouche A, Breysse D, Hornain H, Didry O, Marchand J (2000) A new image analysis technique for the quantitative assessment of microcracks in cement-based materials. Cement and Concrete Research 30 (1):25-35. doi:https://doi.org/10.1016/S0008-8846(99)00212-4

19. Litorowicz A (2006) Identification and quantification of cracks in concrete by optical fluorescent microscopy. Cement and Concrete Research 36 (8):1508-1515. doi:https://doi.org/10.1016/j.cemconres.2006.05.011

20. Zhou C, Li K, Pang X (2012) Geometry of crack network and its impact on transport properties of concrete. Cement and Concrete Research 42 (9):1261-1272. doi:https://doi.org/10.1016/j.cemconres.2012.05.017

21. Schindelin J, Arganda-Carreras I, Frise E, Kaynig V, Longair M, Pietzsch T, Preibisch S, Rueden C, Saalfeld S, Schmid B, Tinevez J-Y, White DJ, Hartenstein V, Eliceiri K, Tomancak P, Cardona A (2012) Fiji: an open-source platform for biological-image analysis. Nature Methods 9 (7):676-682. doi:10.1038/nmeth.2019

22. Walker HN, Lane DS, Stutzman PE (2006) Petrographic Methods of Examining Hardened Concrete: A Petrographic Manual. Federal Highway Administration, McLean, VA 
23. Wong HS, Poole AB, Wells B, Eden M, Barnes R, Ferrari J, Fox R, Yio MHN, Copuroglu O, Guðmundsson G, Hardie R, Jakobsen UH, Makoubi K, Mitchinson A, Raybould P, Strongman J, Buenfeld NR (2020) Microscopy techniques for determining water-cement (w/c) ratio in hardened concrete: a round-robin assessment. Materials and Structures 53 (2):25. doi:https://doi.org/10.1617/s11527-020-1458-2

24. Qiao C, Rothstein D (2020) Microstructural Evaluation of Durability of Different Cementitious Mixtures in Microbial Induced Corrosion Environments. Paper presented at the XV International Conference on Durability of Building Materials and Components, Barcelona, Spain, October, 20-23, 2020

25. Katayama T, Tagami M, Sarai Y, Izumi S, Hira T (2004) Alkali-aggregate reaction under the influence of deicing salts in the Hokuriku district, Japan. Materials Characterization 53 (2):105-122. doi:https://doi.org/10.1016/j.matchar.2004.07.003

26. Rothstein D, Qiao C (2020) Accelerated Expansion Test Sample Report: DRP. In: Saouma VE (ed) Diagnosis \& Prognosis of AAR Affected Structures: State-of-the-Art Report of the RILEM Technical Committee 259-ISR. RILEM State-of-the-Art Reports, vol 31, 1 edn. RILEM, p 594. doi:https://doi.org/10.1007/978-3-030-44014-5_16

27. ASTM C856 / C856M-20, Standard Practice for Petrographic Examination of Hardened Concrete (2020). ASTM International, West Conshohocken, PA. doi:https://doi.org/10.1520/C0856_C0856M-20

28. Steger C (1998) An unbiased detector of curvilinear structures. IEEE Transactions on Pattern Analysis and Machine Intelligence 20 (2):113-125. doi:https://doi.org/10.1109/34.659930

29. Qiao C, Suraneni P, Weiss J (2018) Phase diagram and volume change of the $\mathrm{Ca}(\mathrm{OH})_{2}-\mathrm{CaCl}_{2}-\mathrm{H}_{2} \mathrm{O}$ system for varying $\mathrm{Ca}(\mathrm{OH})_{2} / \mathrm{CaCl}_{2}$ molar ratios. Journal of Materials in Civil Engineering 30 (2):04017281. doi:https://doi.org/10.1061/(ASCE)MT.1943-5533.0002145

30. Suryavanshi AK, Scantlebury JD, Lyon SB (1996) Mechanism of Friedel's salt formation in cements rich in tricalcium aluminate. Cement and Concrete Research 26 (5):717-727. doi:https://doi.org/10.1016/s0008$\underline{8846(96) 85009-5}$

31. Birnin-Yauri UA, Glasser FP (1998) Friedel's salt, $\mathrm{Ca}_{2} \mathrm{Al}(\mathrm{OH})_{6}(\mathrm{Cl}, \mathrm{OH}) \cdot 2 \mathrm{H}_{2} \mathrm{O}$ : Its solid solutions and their role in chloride binding. Cement and Concrete Research 28 (12):1713-1723. doi:http://dx.doi.org/10.1016/S0008$\underline{8846(98) 00162-8}$

32. Qiao C, Suraneni P, Then NWY, Choudhary A, Weiss J (2019) Chloride binding of cement pastes with fly ash exposed to $\mathrm{CaCl}_{2}$ solutions at 5 and $23^{\circ} \mathrm{C}$. Cement and Concrete Composites 97:43-53.

doi:https://doi.org/10.1016/j.cemconcomp.2018.12.011

33. Famy C, Scrivener KL, Atkinson A, Brough AR (2001) Influence of the storage conditions on the dimensional changes of heat-cured mortars. Cement and Concrete Research 31 (5):795-803. doi:https://doi.org/10.1016/S0008$\underline{8846(01) 00480-X}$

34. Galan I, Perron L, Glasser FP (2015) Impact of chloride-rich environments on cement paste mineralogy. Cement and Concrete Research 68:174-183. doi:http://dx.doi.org/10.1016/j.cemconres.2014.10.017

35. Arganda-Carreras I, Kaynig V, Rueden C, Eliceiri KW, Schindelin J, Cardona A, Sebastian Seung H (2017) Trainable Weka Segmentation: a machine learning tool for microscopy pixel classification. Bioinformatics 33 (15):2424-2426. doi:https://doi.org/10.1093/bioinformatics/btx180

36. Liao W, Sun X, Kumar A, Sun H, Ma H (2019) Hydration of Binary Portland Cement Blends Containing Silica Fume: A Decoupling Method to Estimate Degrees of Hydration and Pozzolanic Reaction. Frontiers in Materials 6 (78). doi:https://doi.org/10.3389/fmats.2019.00078 


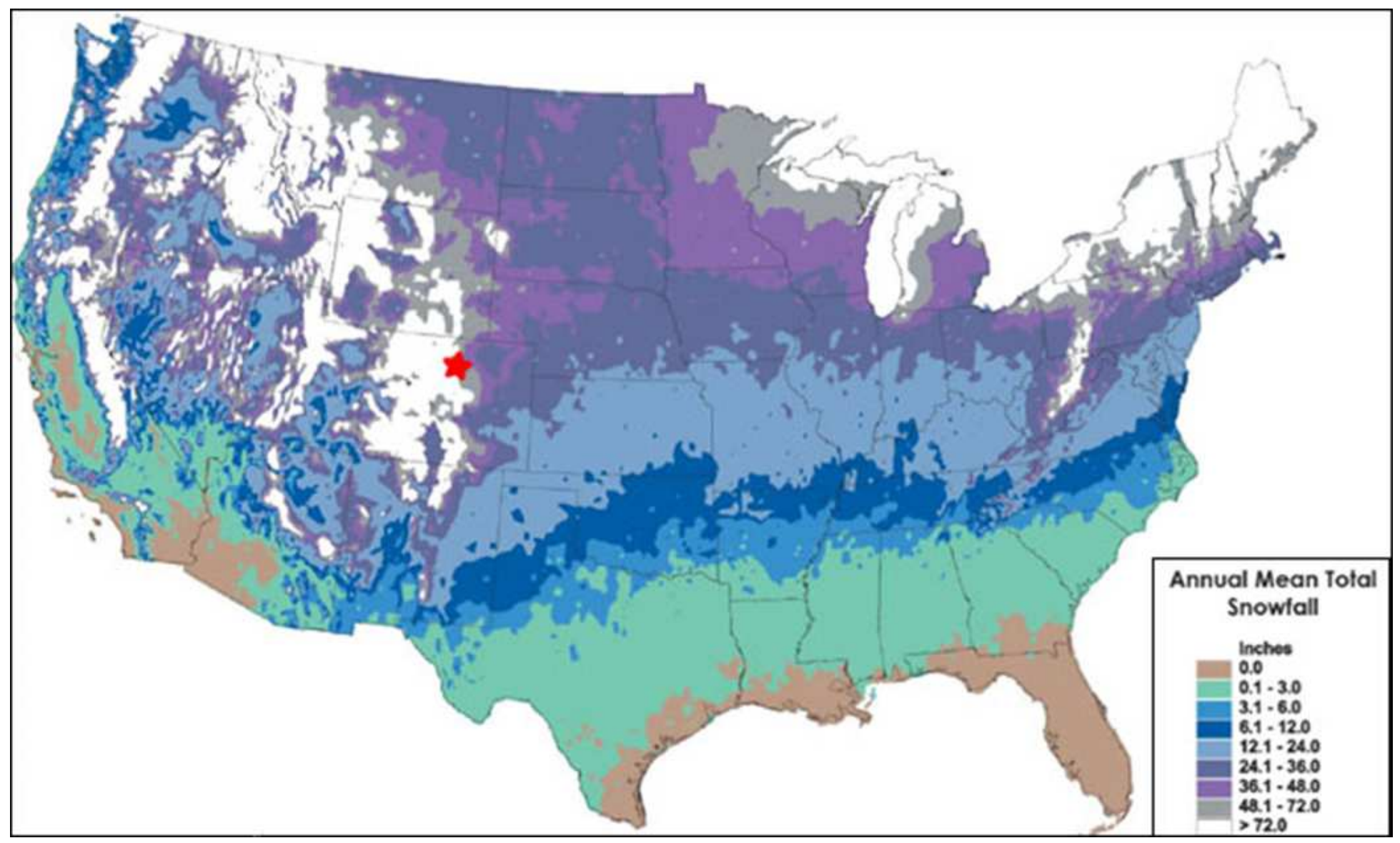

\section{Figure 1}

Average annual snowfall map of the contiguous US from US National Oceanic and Atmospheric Administration (https://www.noaa.gov). The red star indicates the location of the field samples. Note: The designations employed and the presentation of the material on this map do not imply the expression of any opinion whatsoever on the part of Research Square concerning the legal status of any country, territory, city or area or of its authorities, or concerning the delimitation of its frontiers or boundaries. This map has been provided by the authors. 

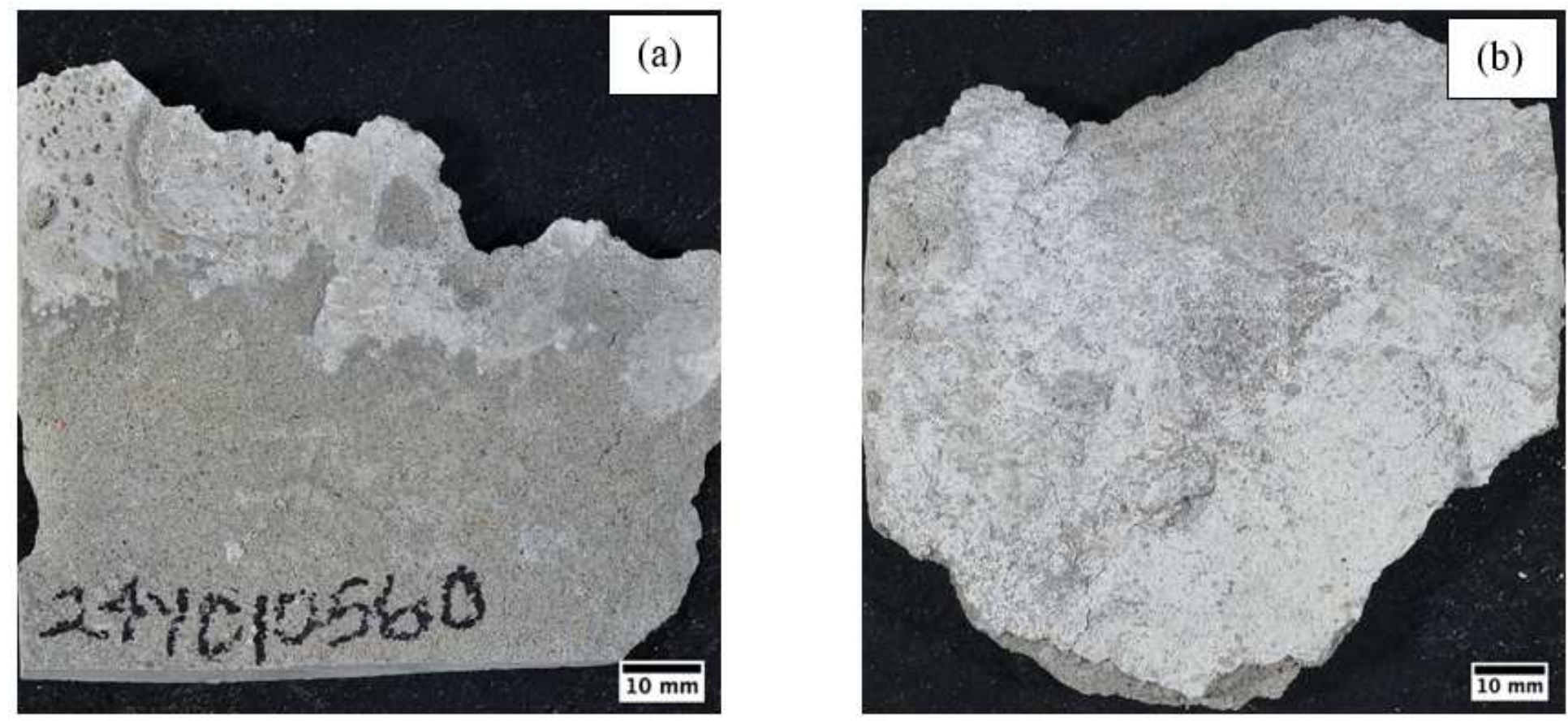

Figure 2

The conditions of the as-received fragments of the undamaged field mortar (a) and the damaged field mortar (b), respectively.
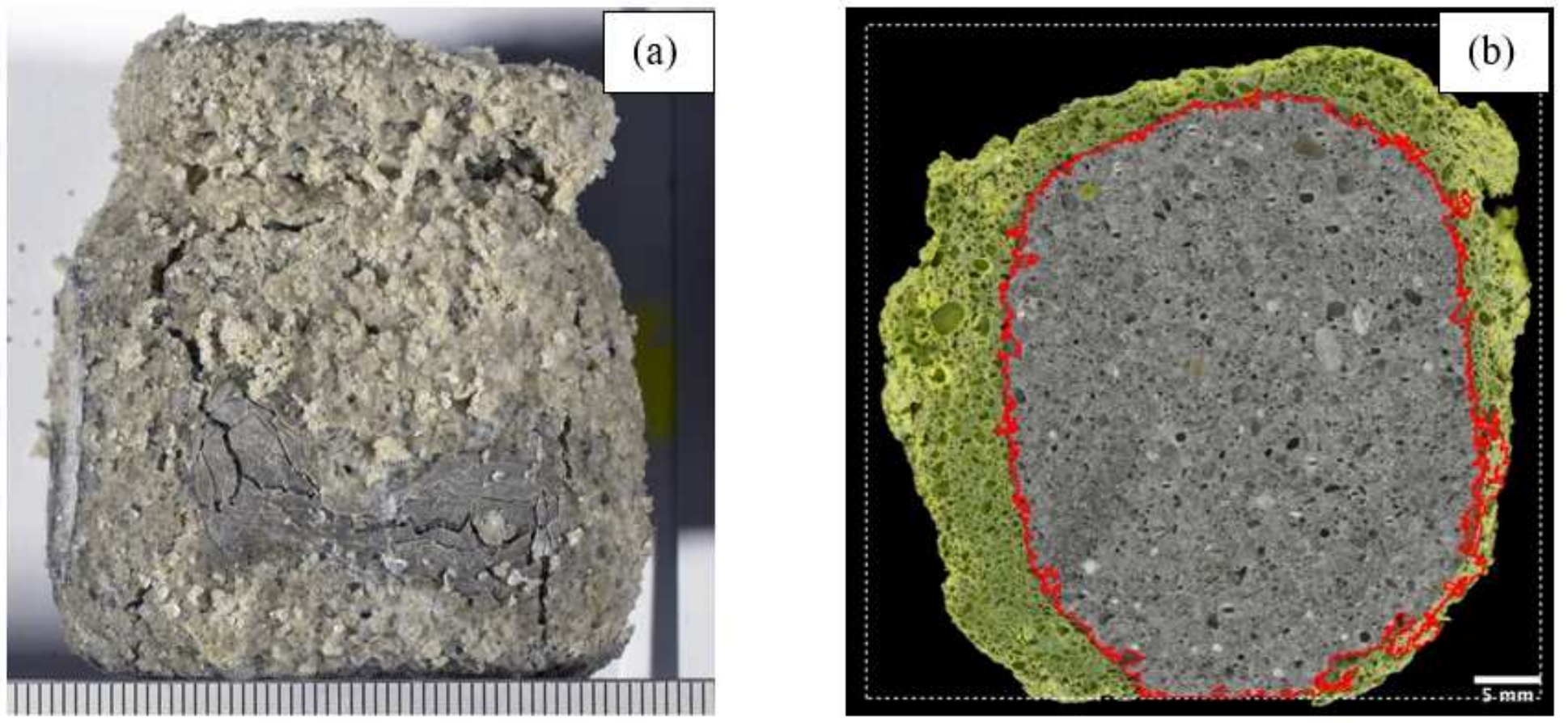

\section{Figure 3}

(a) Photograph showing condition of the lab-cast mortar after 51 freeze-thaw cycles under the submersion of a $25 \mathrm{wt}$ \% $\mathrm{CaCl} 2$ solution. Scale in millimeters. (b) Reflected light photomicrograph of the polished surface of the lab-cast mortar. White square and red curve indicate the original size and the 
remaining intact zone of the sample, respectively. The yellow green color in (b) indicates the epoxied damage zone.
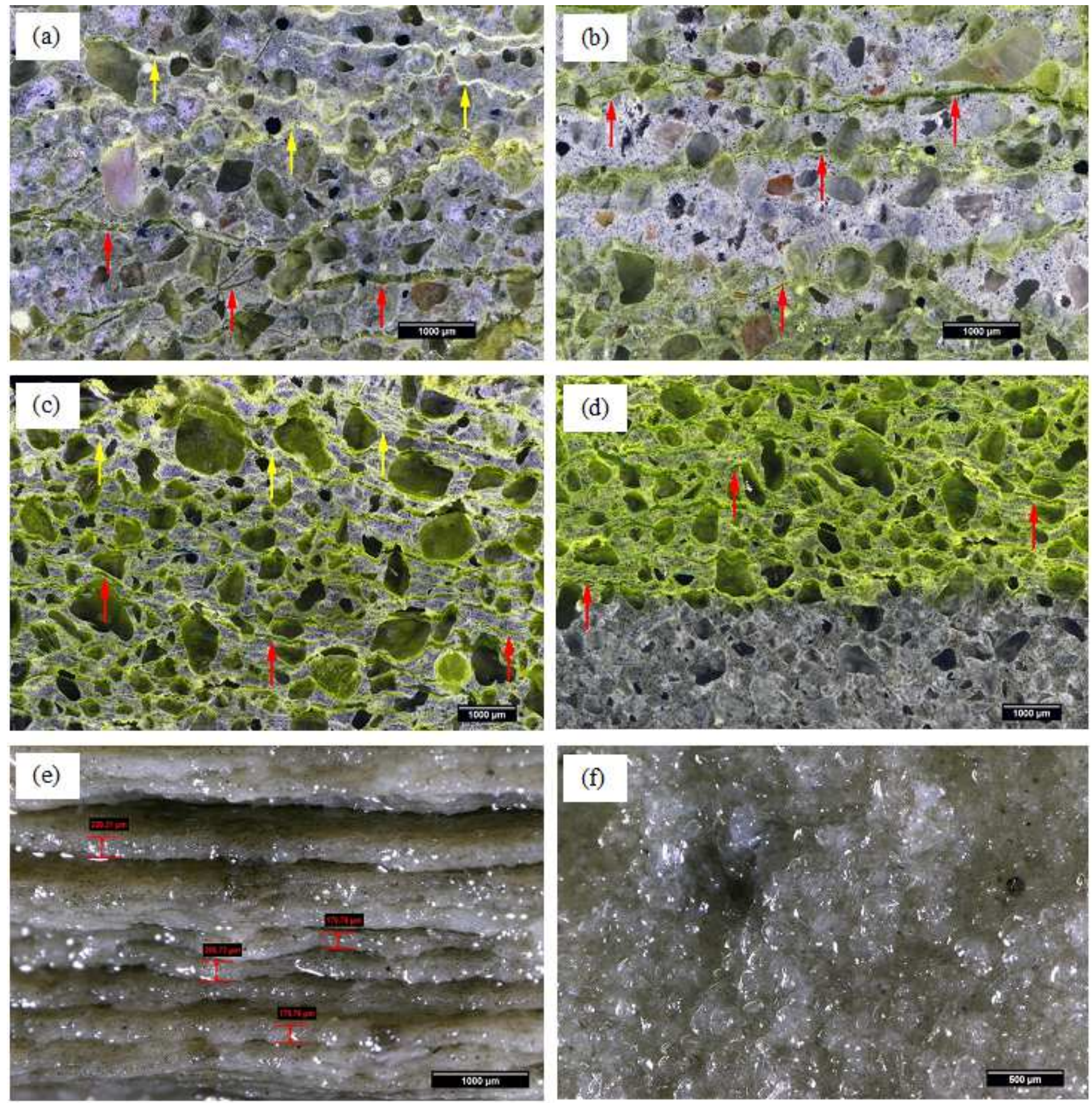

Figure 4

(a)-(d) Reflected light photomicrographs (RLP) of the polished surface of the damaged field mortar (a-b) and lab-cast mortar (c-d) showing horizontal cracks/microcracks at two different depths from the exposure surface, respectively. Zones in (a) and (c) are closer to the exposure surface. Yellow and red arrows indicate cracks/microcracks with and without secondary deposits, respectively. (e) Fresh 
delamination sheets in the damaged lab-cast paste. (f) Transparent secondary deposits on the surface of the delamination sheet in (e).
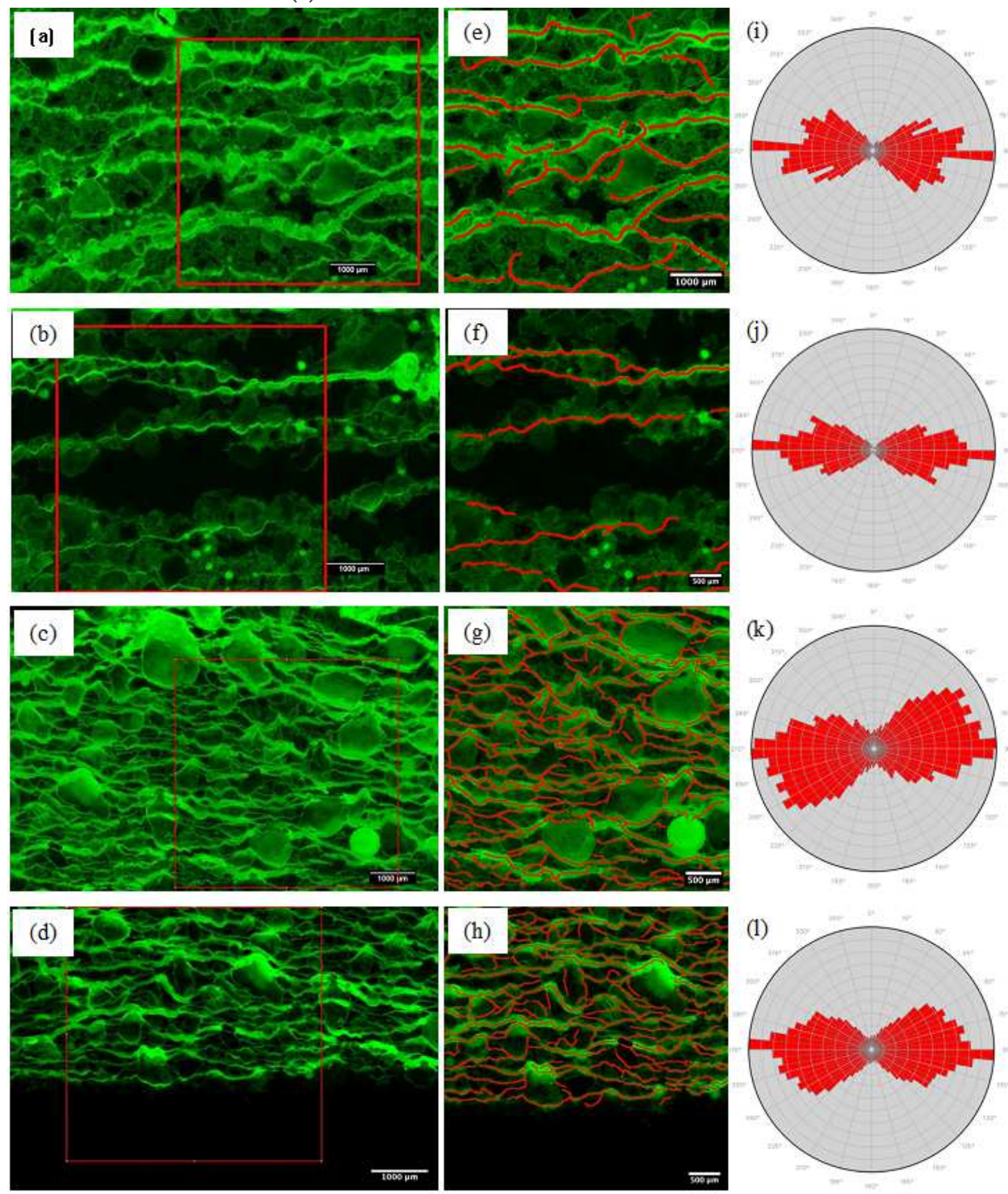

\section{Figure 5}

(a)-(b) Fluorescent reflected light photomicrographs (FRLP) of the polished surface of the damaged field mortar showing cracks/microcracks in the upper and lower zones from the top surface, respectively. (c)(d) FRLP of the polished surface of the lab-cast mortar showing cracks/microcracks in the closer 
(outward) and further (inward) zones from the outer surface, respectively. (e)-(h) Identified crack network in the red zone in (a)-(d). (i)-(I) Rose diagrams showing the cracking orientation in (e)-(h).

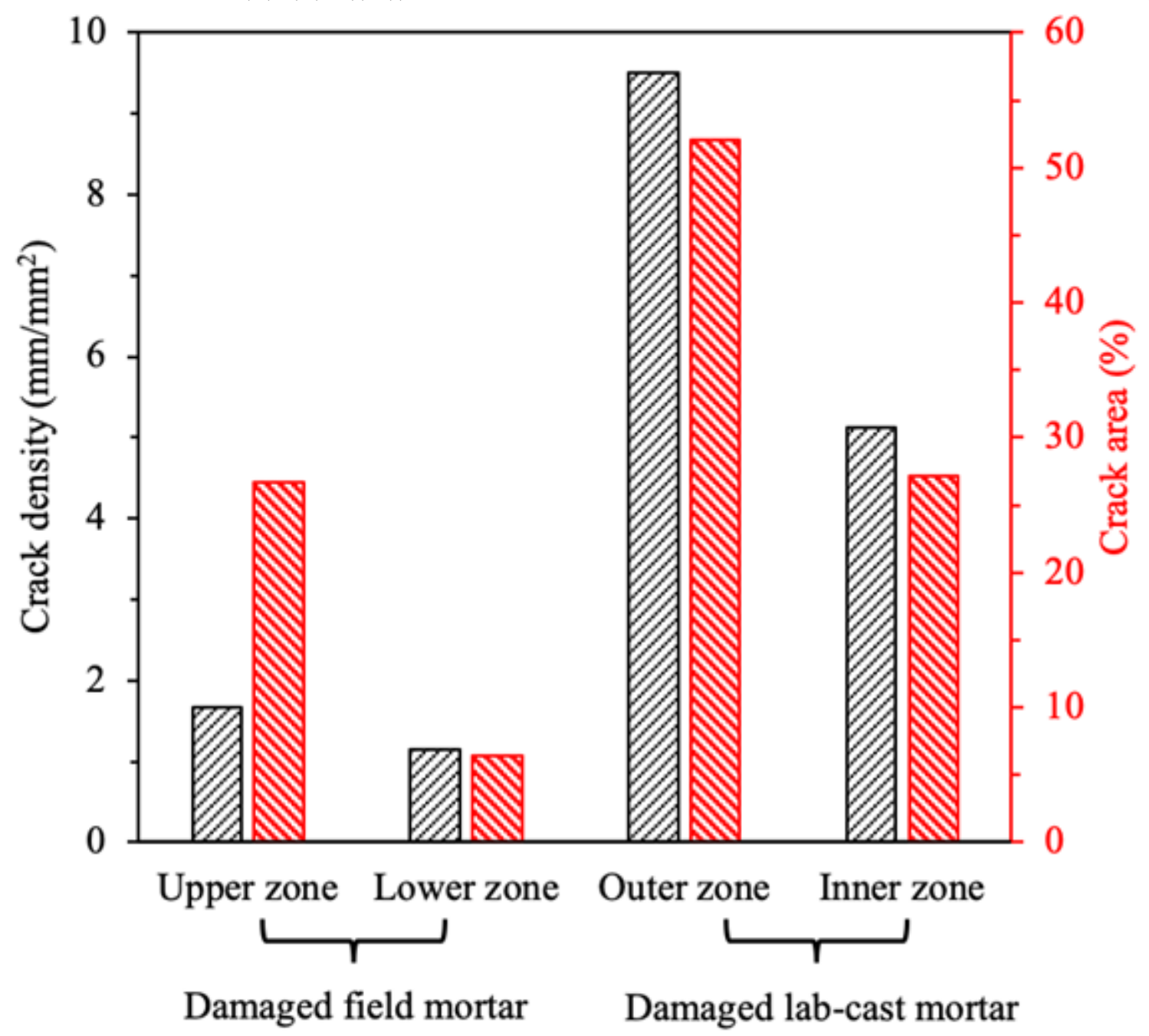

Figure 6

Crack density (left series) and crack area fraction (right series) in different zones of the field damaged field mortar and lab-cast mortar. 

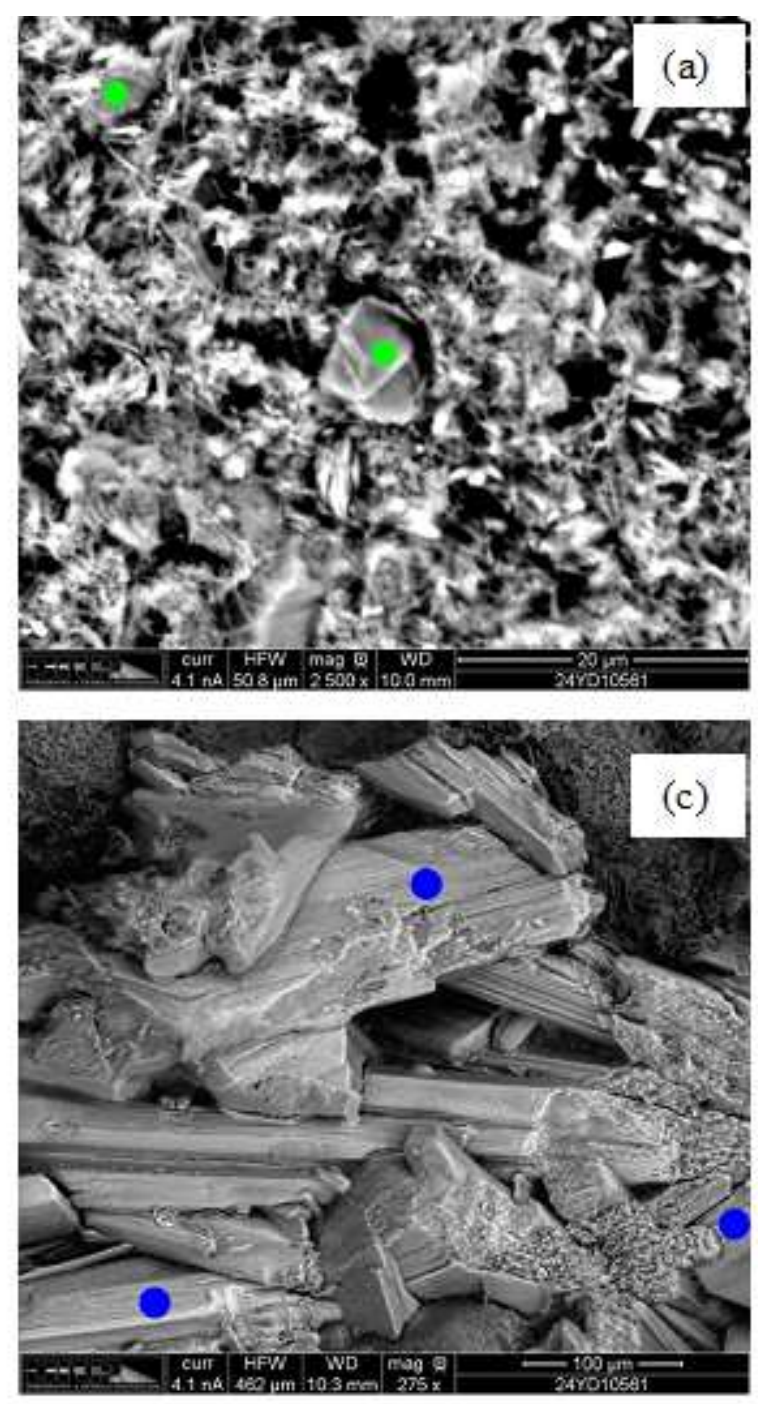
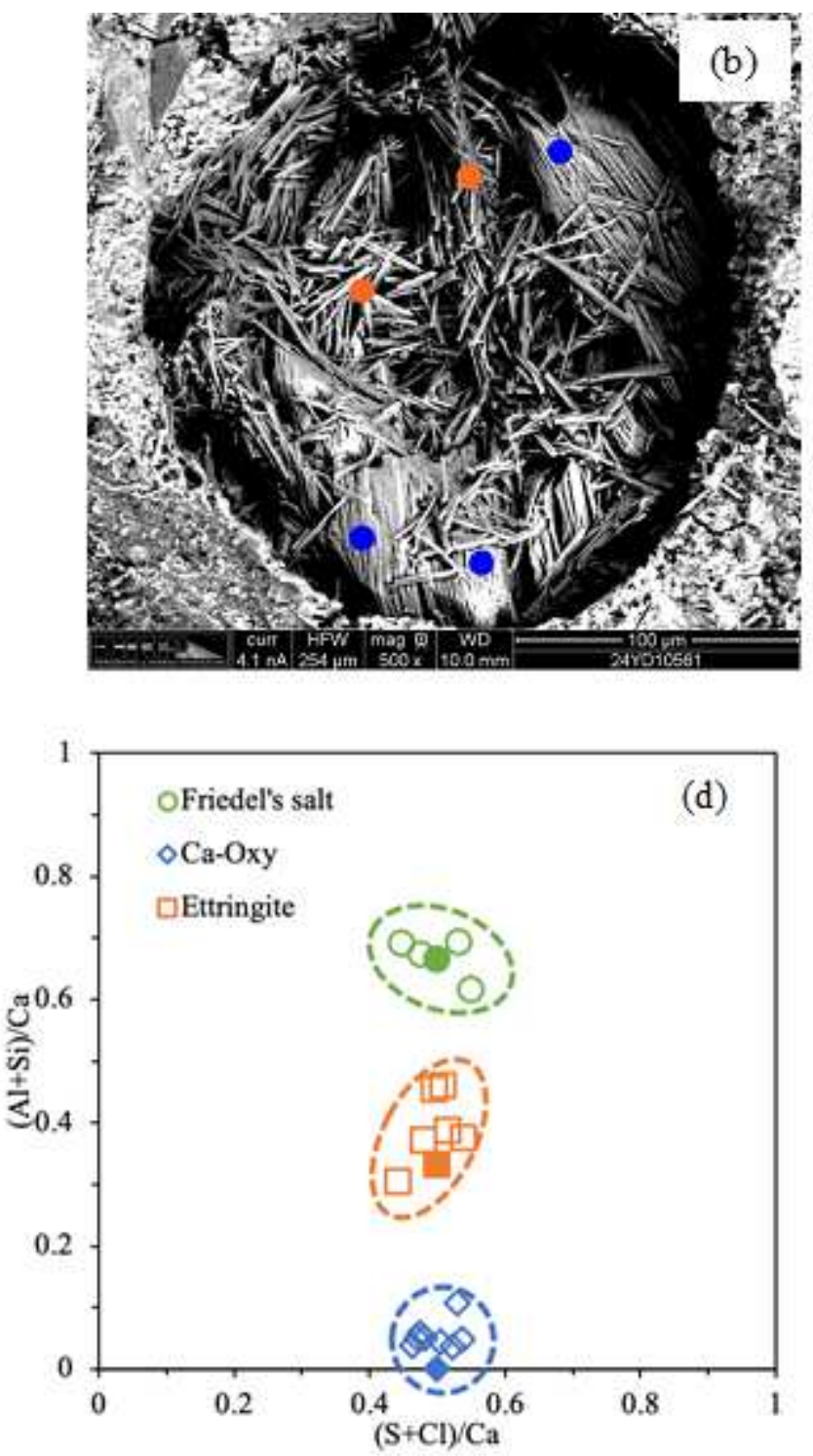

Figure 7

(a)-(c) Backscattered electron (BSE) images of secondary deposits in (a) the paste matrix, (b) an entrained air void and (c) a fresh fracture surface, respectively. Green circles: Friedel's salt, blue diamonds: Ca-Oxy; orange squares: ettringite. (d) Atomic ratios obtained from EDX spectra in zones in (a)-(c). The solid shapes indicate the theoretical composition of the corresponding minerals. 

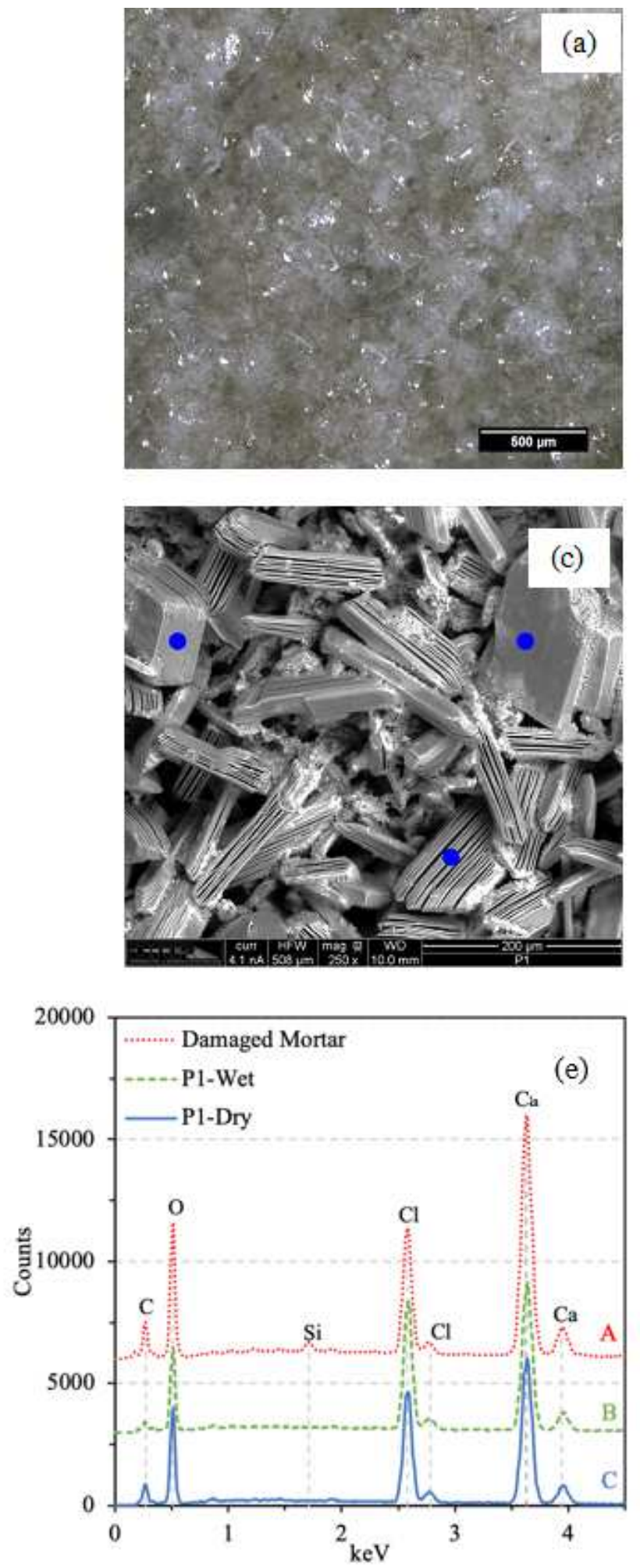
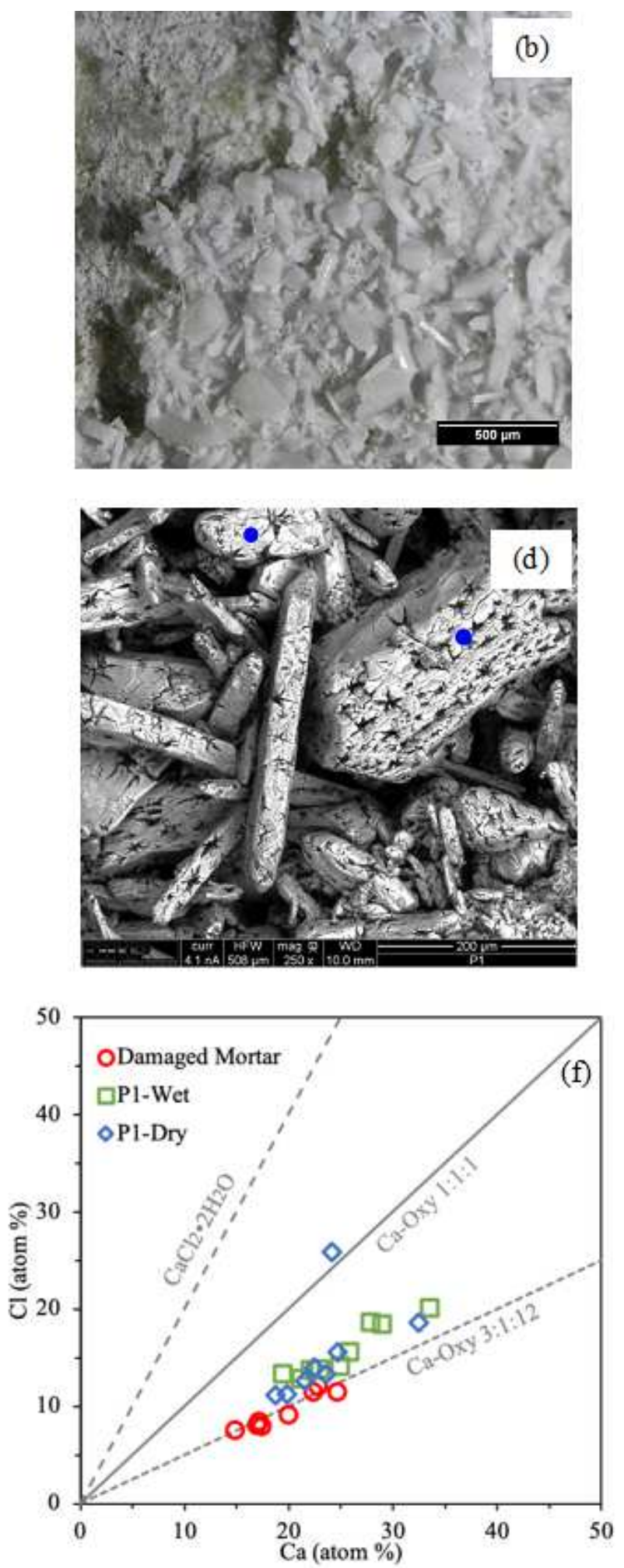

\section{Figure 8}

(a)-(b) RLP and (c)-(d) BSE images of Ca-Oxy (blue solid dots) in (a)/(c) an originally wet condition and (b)/(d) a dried condition on a fracture surface of OPC paste, respectively. (e) EDX spectra obtained from zones in Fig. 5c and Fig. 6a-6b. (f) Relationship between $\mathrm{Ca}$ and $\mathrm{Cl}$ contents of Ca-Oxy observed from EDX overlaid with theoretical Ca-Oxy formulae. 

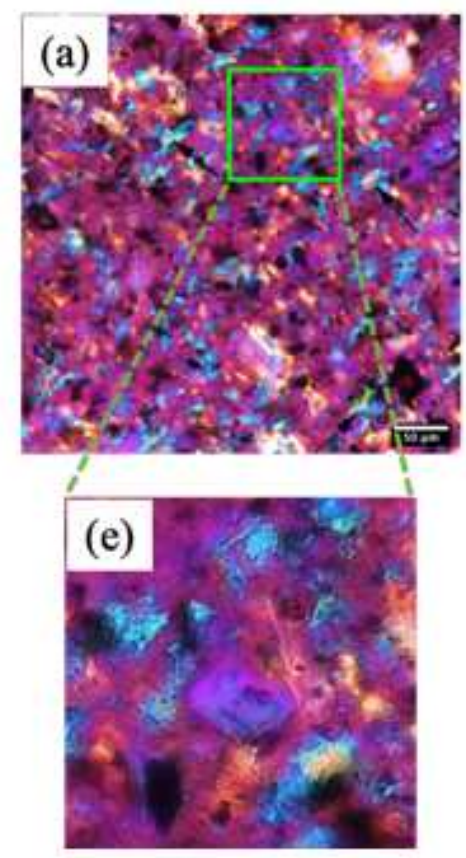
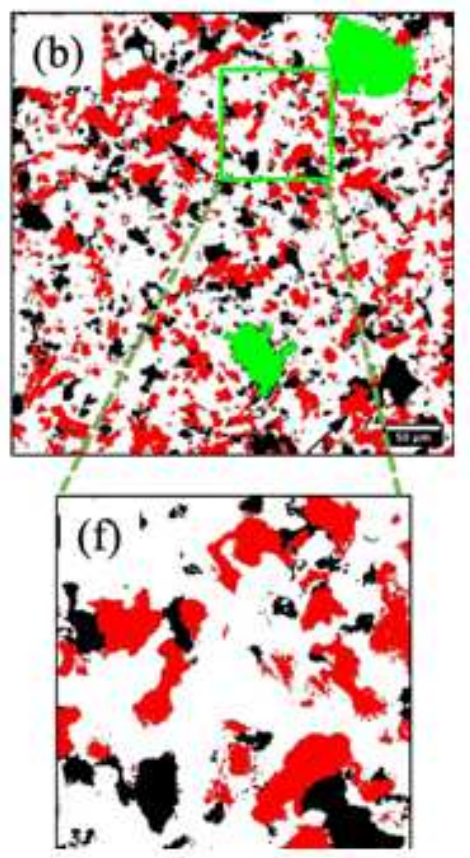
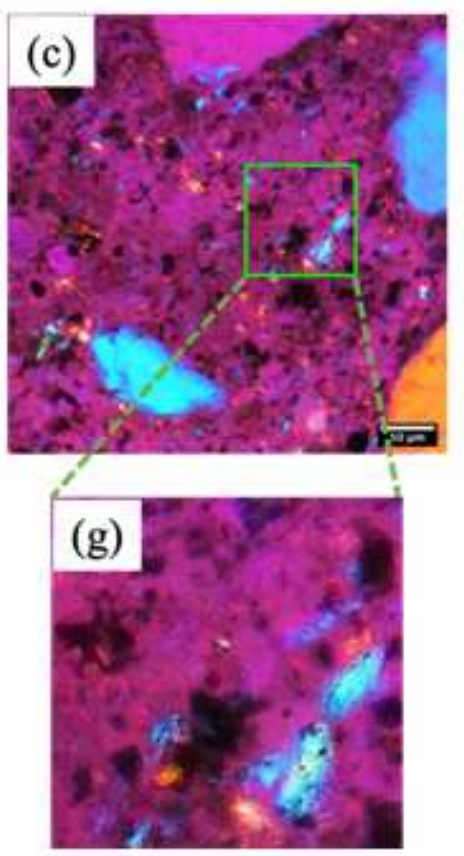
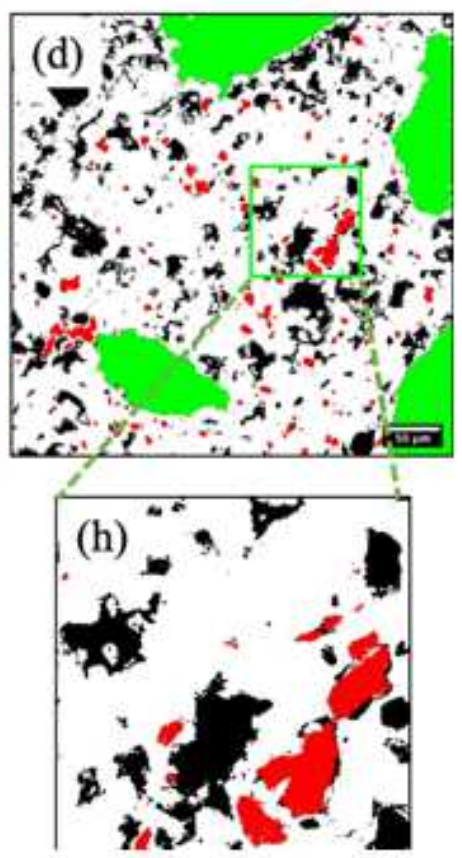

Figure 9

(a)\&(c) Transmitted light photomicrographs showing paste in the middle of the (a) undamaged field mortar and (c) damaged field mortar, respectively, in cross-polarized light with the gypsum first order retardation plate inserted. (b)\&(d) Segmentation images of the photomicrographs in (a) and (c) using 2D Trainable Weka Segmentation in ImageJ [35]. (e)-(h) Zoomed-in images of the corresponding zones in (a)-(d). The size of the zone in (e)-(h) is $100 \mu \mathrm{m}$ by $100 \mu \mathrm{m}$.

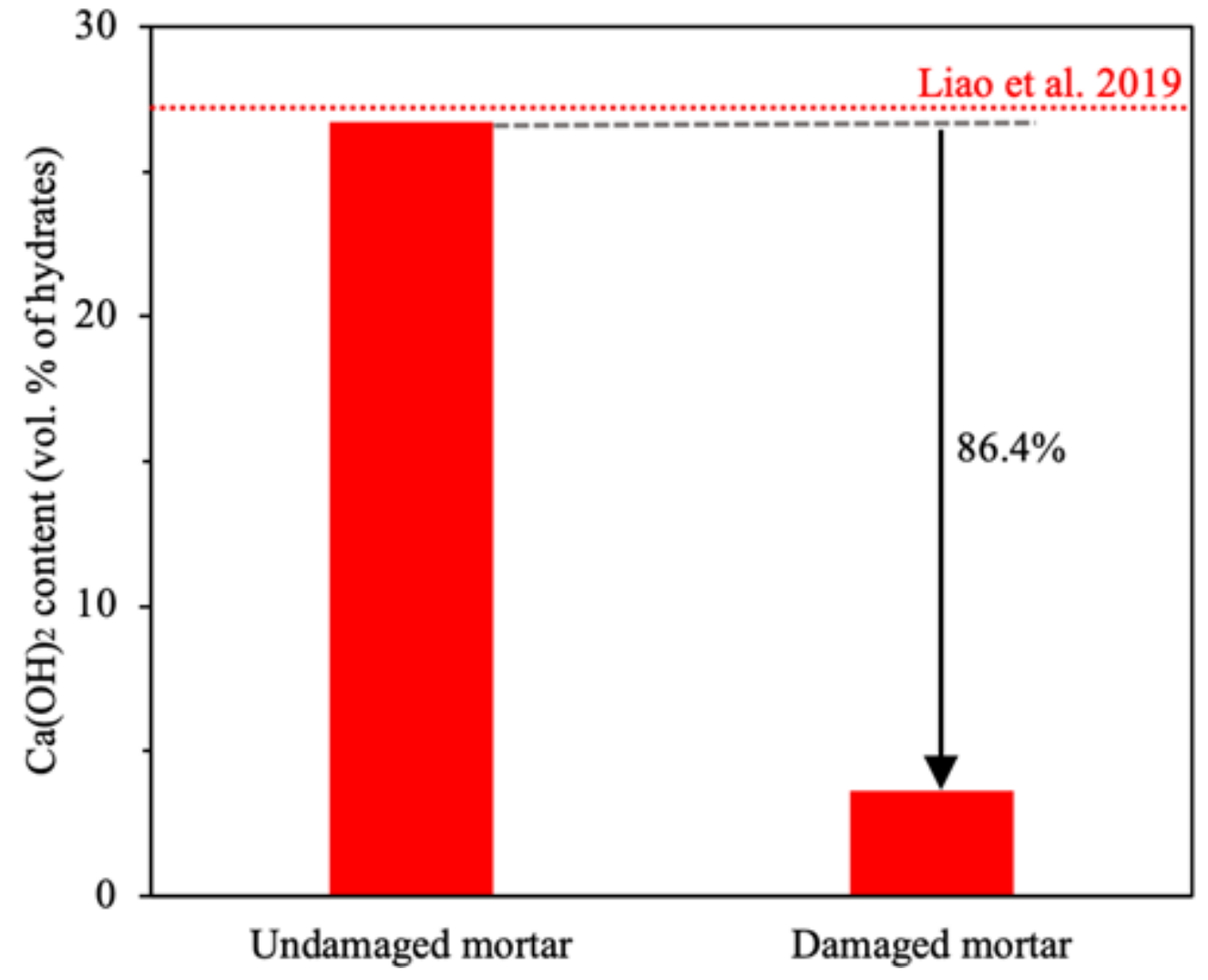


Figure 10

Quantification of $\mathrm{Ca}(\mathrm{OH}) 2$ contents in the mortars using image analysis. The red dotted line indicates the value from Ref. [36]. 